\title{
Therapeutic Effects of the Sphingosine 1-Phosphate Receptor Modulator, Fingolimod (FTY720), on Experimental Autoimmune Encephalomyelitis
}

\author{
Kenji Chiba, Hirotoshi Kataoka, Noriyasu Seki and Kunio Sugahara \\ Mitsubishi Tanabe Pharma Corporation \\ Japan
}

\section{Introduction}

2-Amino-2-[2-(4-octylphenyl)ethyl]propane-1,3-diol hydrochloride (FTY720, fingolimod hydrochloride) is an orally active sphingosine 1-phosphate (S1P) receptor modulator with a structure closely related to sphingosine (Adachi et al., 1995; Chiba et al., 1996, 1997) (Fig. 1). FTY720 sequesters circulating mature lymphocytes into the secondary lymphoid organs (SLO) and thymus by long-term down-regulation of S1P receptor type 1 (S1P1) on lymphocytes, and shows potent immunomodulating effects (Brinkmann et al., 2000, 2002a, 2002b, 2004; Chiba et al., 1998, 1999, Chiba, 2005; Matloubian et al., 2004).

It has been previously reported that a potent immunosuppressive natural product, myriocin (ISP-I) can be isolated from a culture broth of Isaria scinclairii, a kind of vegetative wasp (Fujita et al., 1994a, 1994b; Sasaki et al.,1994). The chemical modification of ISP-I led to a novel synthetic compound, FTY720 that has more potent immunomodulating activity and less toxicity than myriocin (Adachi et al., 1995; Fujita et al., 1995, 1996; Kiuchi et al., 2000). FTY720 is highly effective in prolonging allograft survival in various experimental allograft models (Chiba et al., 1996, 1998, 2005; Hoshino et al., 1996; Kawaguchi et al., 1996; Masubuchi et al., 1996; Suzuki et al., 1996, 1998). A striking feature of FTY720 is the induction of a marked decrease in the number of peripheral blood lymphocytes (T cells and B cells) at doses that prolong allograft survival (Chiba et al., 1996, 1998, 1999; Yanagawa et al., 1998a, 1998b, 1999, 2000). The reduction of the number of peripheral blood lymphocytes induced by FTY720 is mainly caused by sequestration of circulating mature lymphocytes into the SLO as lymph nodes and Peyer's patches (Chiba et al., 1998, 1999, Yanagawa et al., 1998a, 1998b).

It has been reported that FTY720 is effectively phosphorylated to FTY720-phosphate (FTY720-P, (S)-enantiomer) (Fig. 1) by sphingosine kinases (Billich et al., 2003; Paugh et al., 2003) and that FTY720-P is a high affinity agonist at four types of S1P receptors (S1P1, S1P3, S1P4, and S1P5) (Brinkmann et al., 2002a, 2002b; Mandala et al., 2002). It is well documented that S1P1 plays an essential role in lymphocyte egress from the SLO to lymph (Brinkmann et al., 2004; Chiba, 2005; Matloubian et al., 2004). FTY720-P induces a long-lasting internalization and degradation of S1P1, reduces S1P responsiveness of lymphocytes, and 
inhibits lymphocyte egress from the SLO (Brinkmann et al 2002a, 2004; Chiba, 2005; Cyster, 2005; Graler et al., 2004, Maeda et al., 2007, Matloubian et al., 2004; Pham et al., 2008). Consequently, FTY720-P acts as a functional antagonist at lymphocytic S1P1 and immunomodulating effects of FTY720 are likely due to inhibition of egress of antigenspecific $\mathrm{T}$ cells from draining lymph nodes.

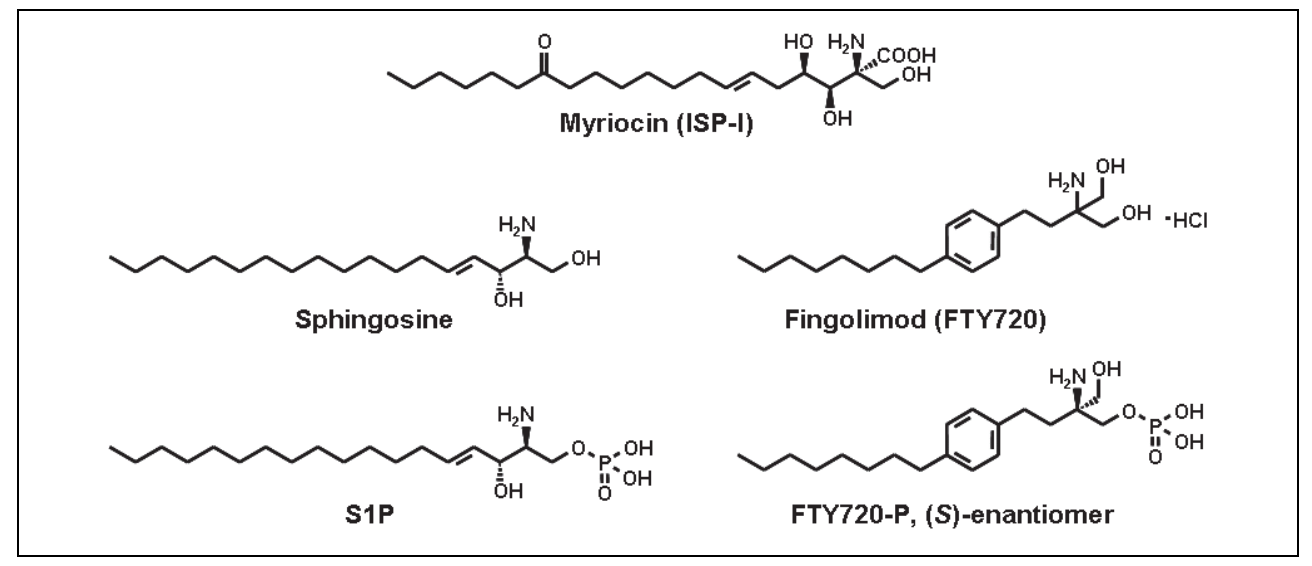

Fig. 1. The Chemical structures of myriocin (ISP-I), sphingosine, sphingosine 1-phospahete (S1P), fingolimod (FTY720) and FTY720-phosphate (FTY720-P).

Multiple sclerosis (MS) is a common and often disabling disease of the central nervous system (CNS). Early active MS lesions are characterized by the presence of infiltrated mononuclear cells around venules and small veins, followed by myelin breakdown and astrogliosis, resulting in irreversible disability (Lubin et al., 1996; Martin et al., 1992; Rammohan, 2003). The etiology of MS remains unknown, but is widely considered to involve the organ-specific autoimmune destruction of CNS myelin mediated by myelinspecific T cells (Anderson et al., 2004; Seamons et al., 2003). Immunomodulating therapy using cyclophosphamide, interferon (IFN)- $\beta$, or glatiramer acetate is widely used for the treatment of MS (Goodkin et al., 1999; Zamvil et al., 2003). Experimental autoimmune encephalomyelitis (EAE), an animal model of human MS, is a demyelinating, inflammatory disease of the CNS and is induced by the immunization of susceptible strains of rats or mice with myelin antigens combined with adjuvant (Kuchroo et al., 1993; Martin et al., 1992, 1995; Owens et al., 1995). It is highly likely that trafficking and infiltration of IFN-ү-expressing type 1 helper T cells (Th1 cells) (Bright et al., 1998; Merrill et al., 1992; Windhagen et al., 1995) and interleukin 17 (IL-17)-expressing helper T cells (Th17 cells) (Bettelli et al., 2006; Komiyama et al., 2006; Kroenke et al., 2008; Langrish et al., 2005; Steinman, 2010; Stromnes et al., 2008) into the CNS play an important role in the development and progression of EAE because myelin antigen-specific Th17 cells and Th1 cells can be found in the blood, lymphoid tissues and CNS in EAE and MS.

There are several reports on ameliorating effects of FTY720 on EAE in mice and rats (Balatoni et al., 2007; Brinkmann et al., 2002a; Chiba et al., 2011; Foster et al., 2007; Fujino et al., 2003; Kataoka et al., 2005; Webb et al., 2004). In myelin basic protein (MBP)-induced EAE in LEW rats, prophylactic administration of FTY720 at 0.1 to $1 \mathrm{mg} / \mathrm{kg}$ almost completely 
prevents the development of EAE symptoms and EAE-associated histological change in the spinal cords (Fujino et al., 2003; Kataoka et al. 2005). In myelin oligodendrocyte glycoprotein (MOG)-induced EAE in DA rats, prophylactic therapy of FTY720 protects against the emergence of EAE symptoms, neuropathology, and disturbances to visual and somatosensory evoked potentials (Foster et al., 2007, Balatoni et al., 2007). Consistent with rat EAE, development of EAE induced by myelin proteolipid protein (PLP) in SJL/J mice is almost completely prevented and infiltration of CD4 T cells into spinal cord is decreased by prophylactic treatment with FTY720 and FTY720-P (Webb et al., 2004; Kataoka et al., 2005). When FTY720 or FTY720-P is given after establishment of EAE in SJL/J mice, marked therapeutic effects on EAE are observed accompanying with reduction of demyelination and infiltration of CD4 T cells in the spinal cords (Chiba et al., 2011; Kataoka et al., 2005; Webb et al., 2004). Similar therapeutic effects by FTY720 are obtained in MOG-induced EAE in C57BL/ 6 mice (Chiba et al., 2011; Kataoka et al., 2005, Seki et al., 2010).

In this chapter, we demonstrate the prophylactic and therapeutic effects of FTY720 on EAE in rats and mice using MBP, myelin PLP or MOG as myelin antigens (Chiba et al., 2011; Kataoka et al., 2005, Seki et al., 2010). Our findings suggest that FTY720 is more efficacious in mouse EAE as compared with rm-IFN- $\beta$ and that the ameliorating effects of FTY720 on EAE are likely due to reduction of the infiltration of myelin antigen-specific Th17 and Th1 cells into the CNS.

On the other hand, it has been well documented that neural cells express S1P receptors and FTY720 can distribute into the CNS beyond blood brain barrier (Brinkmann, 2009). Recently, it has been strongly suggested that FTY720-P directly acts as a functional antagonist at S1P1 on not only lymphocytes but also neural cells, particularly astrocytes because the therapeutic effects of FTY720 on EAE was lost in CNS mutants lacking S1P1 on astrocytes but not neuron (Choi et al, 2011). Since FTY720 possesses a completely new mechanism of action, FTY720 should provide a useful therapeutic approach for MS.

\section{Discovery of FTY720 from a natural product, myriocin}

A potent immunosuppressive natural product, myriocin was isolated from a culture broth of Isaria sinclairii, a kind of vegetative wasp that is an "eternal youth" nostrum in traditional Chinese herbal medicine (Fujita et al., 1994a, 1994b; Sasaki et al., 1994). Chemical modification of myriocin yielded a new compound, FTY720 (Fig. 1), which has more potent immunomodulating activity and less toxicity than myriocin (Adachi et al., 1995; Fujita et al., 1995, 1996; Kiuchi et al., 2000). FTY720 at an oral dose of $0.1 \mathrm{mg} / \mathrm{kg}$ or higher significantly prolongs allograft survival in experimental skin, cardiac and renal allotransplantation models (Chiba et al., 1996, 1997, 1998; Hoshino et al., 1996; Kawaguchi et al., 1996; Masubuchi et al., 1996; Suzuki et al., 1996, 1998). Unlike calcineurin inhibitors, FTY720 does not impair lymphocyte function including $\mathrm{T}$ cell activation and production of Th1 cellassociated cytokines by antigen stimulation (Chiba et al., 1996, 1997, 1998; Yanagawa et al., 1998a). Moreover, we have demonstrated that FTY720 does not inhibit serine palmitoyltransferase that is the first enzyme in sphingolipid biosynthesis and is the target enzyme of myriocin (Fujita et al., 1996).

A striking feature of FTY720 is the induction of a marked decrease in the number of peripheral blood lymphocytes at doses that display an immunomodulating activity (Chiba et al., 1996, 1997, 1998, Li et al., 2002; Yagi et al., 2000; Yanagawa et al., 1998a, 1998b). In rats, 
the number of lymphocytes (T cells and B cells) in peripheral blood decreases dramatically within 6 hours after oral administration of FTY720 at 0.1 to $1 \mathrm{mg} / \mathrm{kg}$ (Chiba et al., 1998, 1999). To clarify the mechanism of lymphocyte reduction by FTY720, distribution of lymphocytes in blood, lymph, and various SLO was analyzed after FTY720 administration in rats (Chiba et al., 1998). When FTY720 at an oral dose of $0.1 \mathrm{mg} / \mathrm{kg}$ or higher is given to rats or mice, the number of lymphocytes is decreased markedly in the peripheral blood and thoracic duct lymph whereas that in the SLO is increased significantly. Intravenous transfusion of fluorescein-labelled lymphocytes into rats reveals that the labelled lymphocytes are accumulated in the SLO by FTY720 administration (Chiba et al, 1998). These data suggest that FTY720 induces sequestration of circulating mature lymphocytes into SLO and decreases the number of lymphocytes in peripheral blood, and lymph. Thus, sequestration of circulating mature lymphocytes is presumed to be the main mechanism of immunomodulating activity of FTY720. As reported previously, immunohistochemical staining and flow cytomeric analysis revealed that FTY720 decreases the infiltration of T cells into the allograft at doses showing immunomodulating effects (Chiba, 2005, Yanagawa et al, 1998a, 1999, 2000). These findings strongly suggest that FTY720 exerts immunomodulating activity by decreasing $\mathrm{T}$ cell infiltration into inflammatory sites.

\section{Mechanism of action of FTY720, S1P receptor modulator}

Circulation of mature lymphocytes among the SLO, lymph and blood plays a central role in the establishment of the immune response to foreign antigens. Homing of lymphocytes from blood into the SLO beyond high endothelial venules is highly dependent on the interaction between the CC-chemokine ligand (CCL) 19, CCL21, CXC-chemokine ligand (CXCL) 13, and their receptors: CC-chemokine receptor (CCR) 7 and CXC-chemokine receptor (CXCR) 5 on lymphocytes. On the other hand, throughout the analyses of the mechanism of action of FTY720, it is clarified that S1P and its receptor, S1P1 play an essential role in lymphocyte egress from the SLO to lymph (Brinkmann et al 2002a, 2004; Chiba, 2005; Chiba et al., 2006; Cyster, 2005; Lo et al., 2005; Maeda et al., 2007, Matloubian et al., 2004; Pham et al., 2008). Reverse pharmacological approaches have been performed to elucidate that FTY720 is phosphorylated by sphingosine kinases (Billich et al., 2003; Paugh et al., 2003) and FTY720phosphate (FTY720-P) acts as a high affinity agonist of 4 types of S1P receptors (S1P1, S1P3, S1P4, and S1P5) (Brinkmann et al, 2002a, 2002b; Mandala et al., 2002). After oral or intravenous FTY720 administration, the plasma concentration of FTY720-P was 2 to 6 times higher than FTY720 (Brinkmann et al 2002a).

$\mathrm{S} 1 \mathrm{P}$, a pleiotropic lysophospholipid mediator is converted primarily by the phosphorylation of sphingosine by sphingosine kinases and stimulates multiple signalling pathways resulting in calcium mobilization from intracellular stores, polymerization of actin, chemotaxis/migration, and escape from apoptosis (Hla et al., 2001, Pyne et al.; 2000). S1P is predominantly released by red blood cells or platelets and is found in significant amounts (100 to $400 \mathrm{nM}$ ) in serum (Kimura et al, 2001). S1P binds with nano-molar affinities to five related G-protein-coupled receptors, termed S1P1-5 (Brinkmann et al., 2002a, 2002b; Chiba, 2005; Mandala et al. 2002) (Fig. 2). It has been reported that S1P1 is essential for lymphocyte recirculation and that S1P1 regulates lymphocyte egress from the SLO (Brinkmann et al 2002, 2004; Chiba, 2005; Cyster, 2005; Maeda et al., 2007, Matloubian et al., 2004; Pham et al., 2008). In mice whose hematopoietic cells lack a single S1P receptor, S1P1, there are no T cells 
in the periphery because mature T cells are unable to exit SLO (Matloubian et al., 2004). Moreover, S1P1-dependent chemotactic responsiveness is suggested to be up-regulated in lymphocytes before exit from the SLO, whereas S1P1 is down-regulated during peripheral lymphocyte activation, and this is associated with retention of lymphocytes in the SLO (Lo et al, 2005).

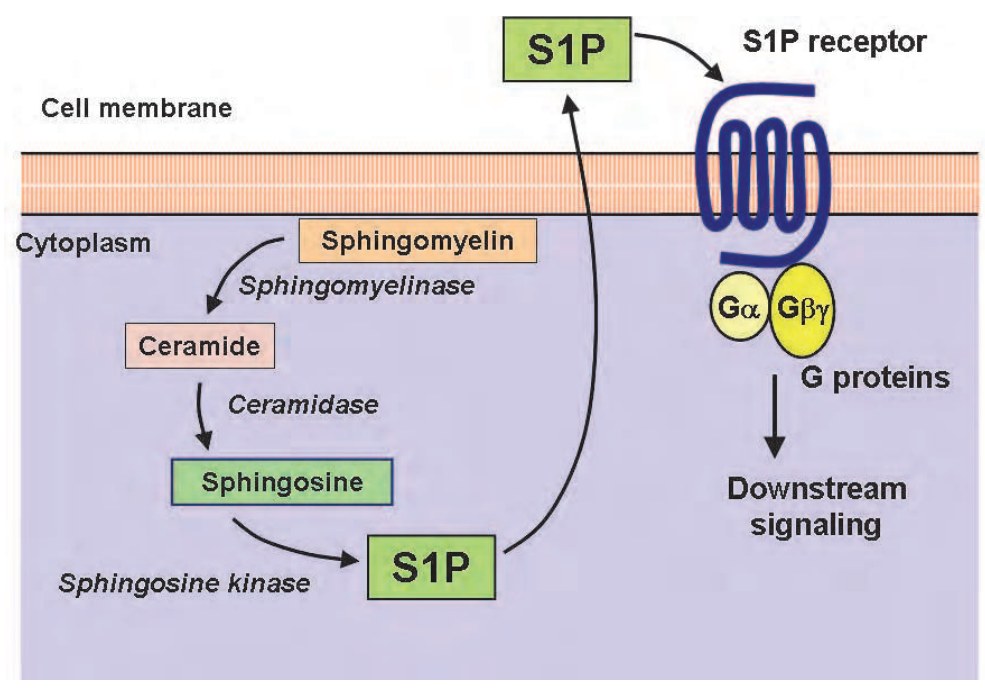

Fig. 2. Generation of S1P and interaction with S1P receptor. S1P is generated primarily by the phosphorylation of intracellular sphingosine by sphingosine kinases and binds to five related G-protein-coupled S1P receptors (S1P1-5).

FTY720 treatment down-regulates S1P1, creating a temporary pharmacological S1P1-null state in lymphocytes, providing an explanation for the mechanism of FTY720-induced lymphocyte sequestration (Graler et al., 2004; Matloubian et al., 2004). Since S1P1 surface expression on lymphocytes is highly dependent on the extracellular concentration of S1P, S1P1 on lymphocytes is down-regulated in the blood, up-regulated in SLO and downregulated again in the lymph (Cyster, 2005; Lo et al., 2005). Thus, it is proposed that cyclical modulation of S1P1 surface expression on circulating lymphocytes by S1P contributes to establishing their transit time in SLO.

We have confirmed that only the (S)-enantiomer of FTY720-P can bind to four types of S1P receptors (S1P1, 3, 4, 5) at nano-molar concentrations, but not S1P2, whereas FTY720 up to 10,000 nM does not bind S1P receptors (Chiba, 2005, Kiuchi et al., 2005). FTY720-P shows agonist activity for S1P1 at nano-molar concentrations using extracellular signal regulated kinase 1/2 (ERK1/2) phosphorylation assay and subsequently induces long-term internalization of S1P1 in Chinese hamster ovary $(\mathrm{CHO})$ cells stably expressing human S1P1 (Chiba, 2005; Chiba et al.; 2006, Maeda et al., 2007). The internalization of S1P1 by FTY720-P appears to be maintained longer than that by S1P and the difference between FTY720-P and S1P seems to be due to the distinct stability of FTY720-P and S1P for degradation by S1P lyase. S1P at concentrations of 10 to $100 \mathrm{nM}$ induces migration of lymph node CD4 ${ }^{+} \mathrm{T}$ cells 
in mice. By contrast, the pretreatment with FTY720-P effectively inhibits the migration of $\mathrm{CD}^{+}{ }^{+} \mathrm{T}$ cells toward S1P (Chiba, 2005; Chiba et al.; 2006, Maeda et al., 2007). Based on these results, it is presumed that FTY720-P converted from FTY720 acts as a functional antagonist at S1P1 receptor by internalization and degradation of the S1P1, reduces S1P responsiveness of lymphocytes, and inhibits S1P1-dependent lymphocyte egress from SLO (Fig. 3).

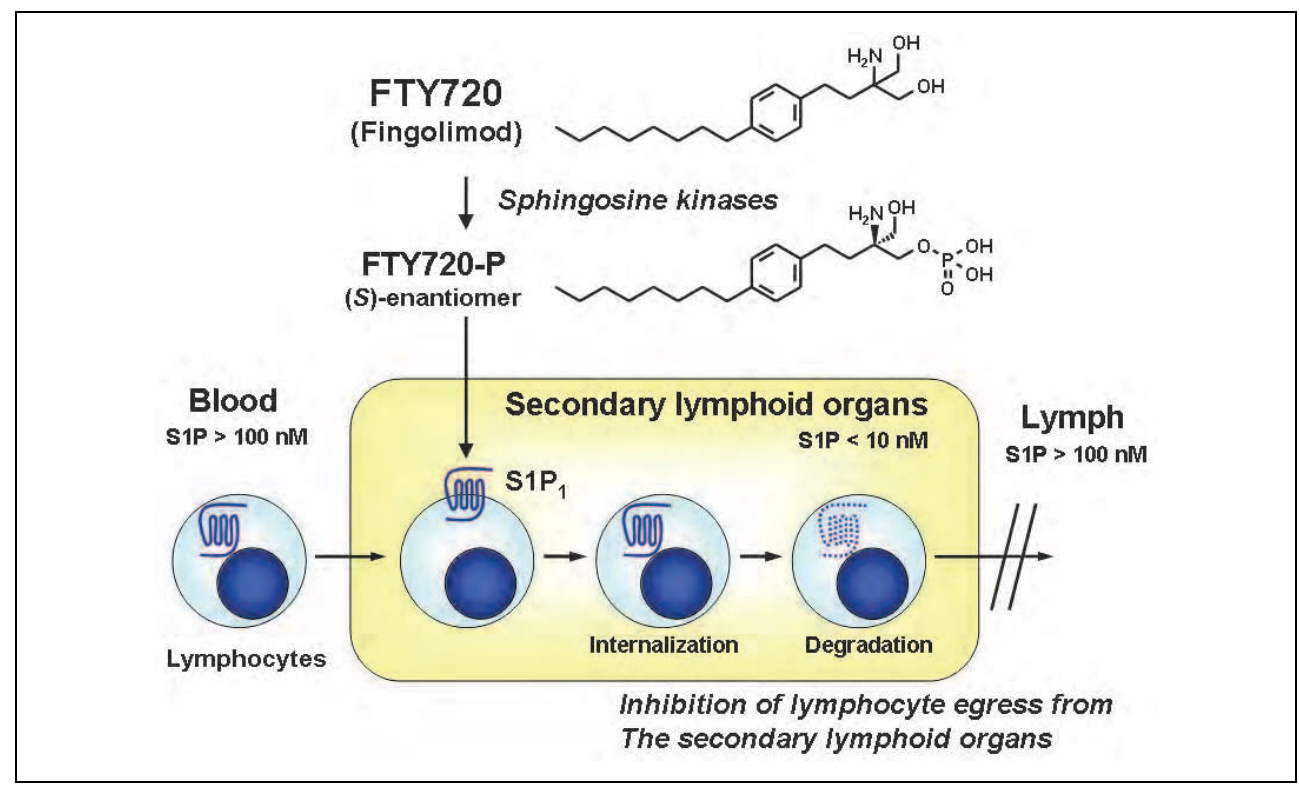

Fig. 3. FTY720-P converted from FTY720 inhibits S1P/S1P1 axis-dependent lymphocyte egress from SLO by functional antagonism (internalization and degradation) at lymphocytic S1P1.

\section{Effects of FTY720 on MBP-induced EAE in LEW rats}

We examined the prophylactic and therapeutic effects of FTY720 on EAE induced by immunization with MBP in LEW rats (Kataoka et al., 2005). All of the LEW rats in the vehicle-treated control group developed EAE-associated clinical symptoms 10 days after immunization with guinea pig MBP, reaching a maximal level on day 13 followed by a gradual decline (Fig. 4A). Elevation of EAE scores was significantly inhibited in groups given FTY720 prophylactically at oral doses of $0.1,0.3$, and $1 \mathrm{mg} / \mathrm{kg}$ for 20 days from the day of MBP immunization. Consistent with EAE-associated symptoms, the histological scores in FTY720-treated groups decreased significantly and dose-dependently as compared with the vehicle-treated control group.

To evaluate the therapeutic potential of FTY720 in MBP-induced EAE in LEW rats, the administration was started from the day of EAE onset (Fig. 4B). In the vehicle-treated control group, EAE had developed by day 9 after immunization and reached a maximal 
level on day 11 to 13. Thereafter, the mean of EAE scores remained within the 2 to 3 range until day 20, because 4 out of 8 EAE rats died with severe symptoms in the control group. Therapeutic administration of FTY720 from the day of EAE onset significantly decreased post-peak EAE-associated clinical signs. Moreover, the therapeutic administration of FTY720 resulted in a significant decrease in the histological score of EAE. The infiltration of inflammatory cells into the spinal cords of EAE rats was inhibited in the FTY720-treated group. These data indicate that FTY720 not only has a prophylactic but also a therapeutic potential in MBP-induced EAE in LEW rats.

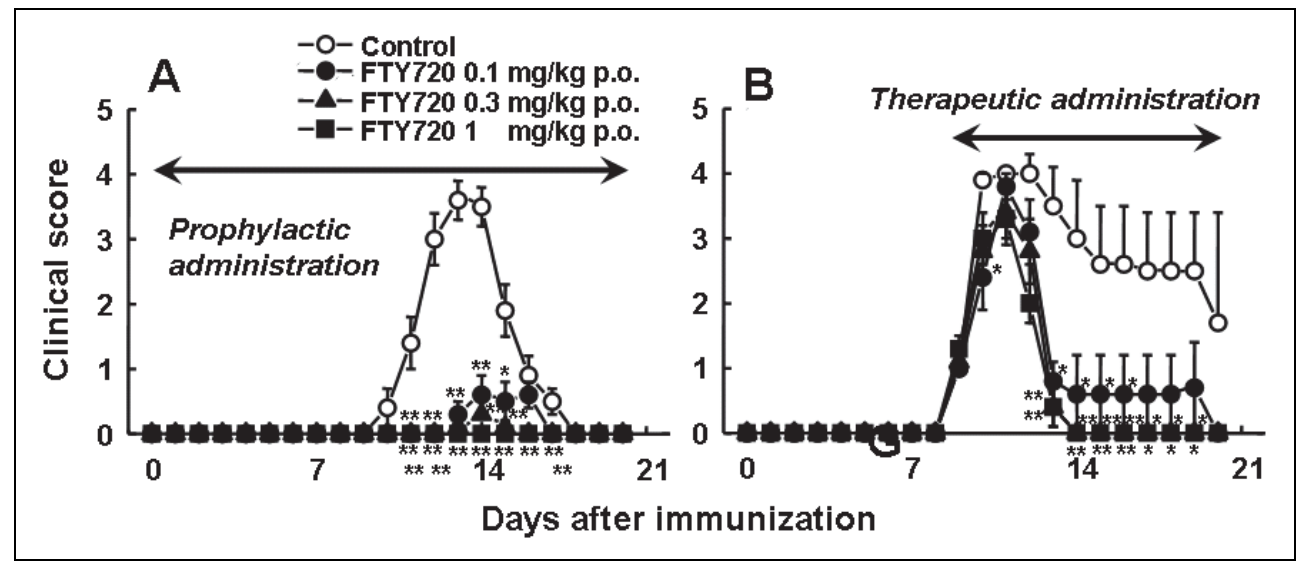

Fig. 4. Prophylactic and therapeutic effects of FTY720 on MBP-induced EAE in LEW rats. LEW rats were immunized with guinea pig MBP $(100 \mu \mathrm{g} / \mathrm{rat})$ and Freund's complete adjuvant. FTY720 was administered orally to MPB-immunized LEW rats every day from the day of immunization (A: prophylactic administration) or the day of onset (B: therapeutic administration) until day 20. Rats in the control group were administered vehicle only. The results are expressed as the mean \pm S.E.M of 8 animals and statistical differences were calculated by Steel's test (non-parametric Dunnett's multiple comparison test, *: $\left.\mathrm{p}<0.05,{ }^{* *}: \mathrm{p}<0.01\right)$.

\section{Effects of FTY720 on PLP-induced EAE in SJL/J mice}

\subsection{Prophylactic effects of FTY720 on PLP-induced EAE in SJL/J mice}

In human MS, neurological symptoms relapse over several years; however MPB-induced EAE in LEW rats was monophasic with no relapse. To clarify the therapeutic potential of FTY720 in human MS more precisely, we evaluated the effect of FTY720 and its active metabolite, FTY720-P on relapsing EAE in SJL/J mice induced by PLP ${ }_{139-151}$ immunization (Chiba et al., 2011; Kataoka et al., 2005). SJL/J mice immunized with PLP $P_{139-151}$ emulsified in Freund's complete adjuvant resulted in the development of EAE-associated clinical symptoms and a decrease in body weight 11 days after immunization. EAE scores rapidly elevated and reached a maximal level on day 15. The first phase of EAE remitted with a low EAE score on day 20 
and spontaneously relapsed thereafter (Fig. 5A). The elevation of EAE-associated clinical score and the loss of body weight were prevented in groups given FTY720 prophylactically at oral doses of 0.1 and $0.3 \mathrm{mg} / \mathrm{kg}$ for 42 days from the day of immunization (Figs. 5). Consistent with MBP-induced EAE in LEW rats, there was no increase in EAE score in the group treated with FTY720 at $1 \mathrm{mg} / \mathrm{kg}$, indicating a complete prevention of PLP $139-151$-induced EAE in SJL/J mice (Kataoka et al., 2005). Almost the same prophylactic effect was observed when FTY720-P at 0.1

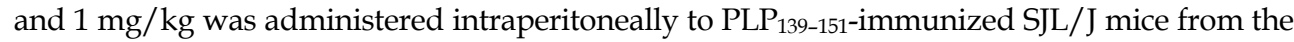
day of immunization. By contrast, prophylactic treatment with recombinant mouse (rm)-IFN- $\beta$ at 10000 IU three times a week intraperitoneally showed no clear effect or no lymphopenia (Kataoka et al., 2005).

The infiltration of inflammatory cells was observed in the spinal cord of SJL/J mice 17 days after immunization with PLP $_{139-151}$ (Kataoka et al., 2005). Prophylactic administration of FTY720 at $1 \mathrm{mg} / \mathrm{kg}$ orally resulted in a marked reduction of the infiltration of inflammatory

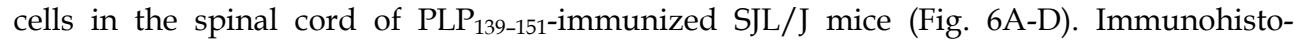
chemical staining analysis using anti- $\mathrm{T}$ cell subset $\mathrm{mAbs}$ revealed the infiltration of $\mathrm{CD} 4^{+} \mathrm{T}$ cells rather than $\mathrm{CD}^{+} \mathrm{T}$ cells into the spinal cord, especially the perivascular area and

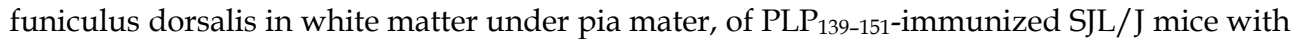
developed EAE. Prophylactic administration of FTY720 at $1 \mathrm{mg} / \mathrm{kg}$ orally markedly decreased the infiltration of $\mathrm{CD}^{+} \mathrm{T}$ cells into the spinal cord as compared with the vehicletreated control EAE group (Fig. 6E-H).

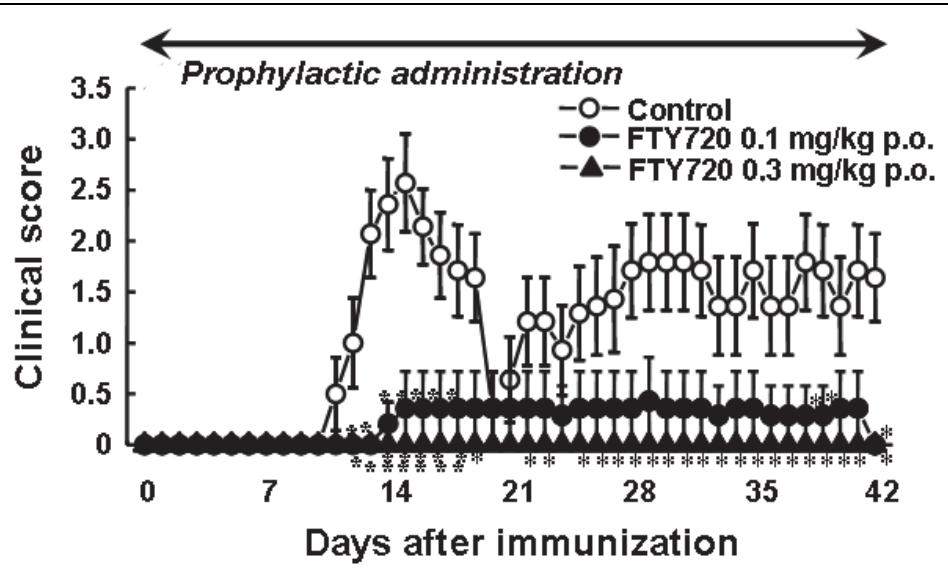

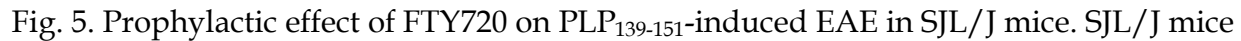
were immunized with PLP $139-151$ (50 $\mu \mathrm{g} /$ mouse) and Freund's complete adjuvant. FTY720 was administered orally to PLP $139-151$-immunized SJL/J mice every day from the day of immunization for 42 days. Mice in the control groups were administered vehicle only. The results are expressed as the mean \pm S.E.M. of 7 animals and statistical differences in clinical scores of EAE were calculated by Steel's test $\left({ }^{*}: \mathrm{p}<0.05,{ }^{* *}: \mathrm{p}<0.01\right)$. 


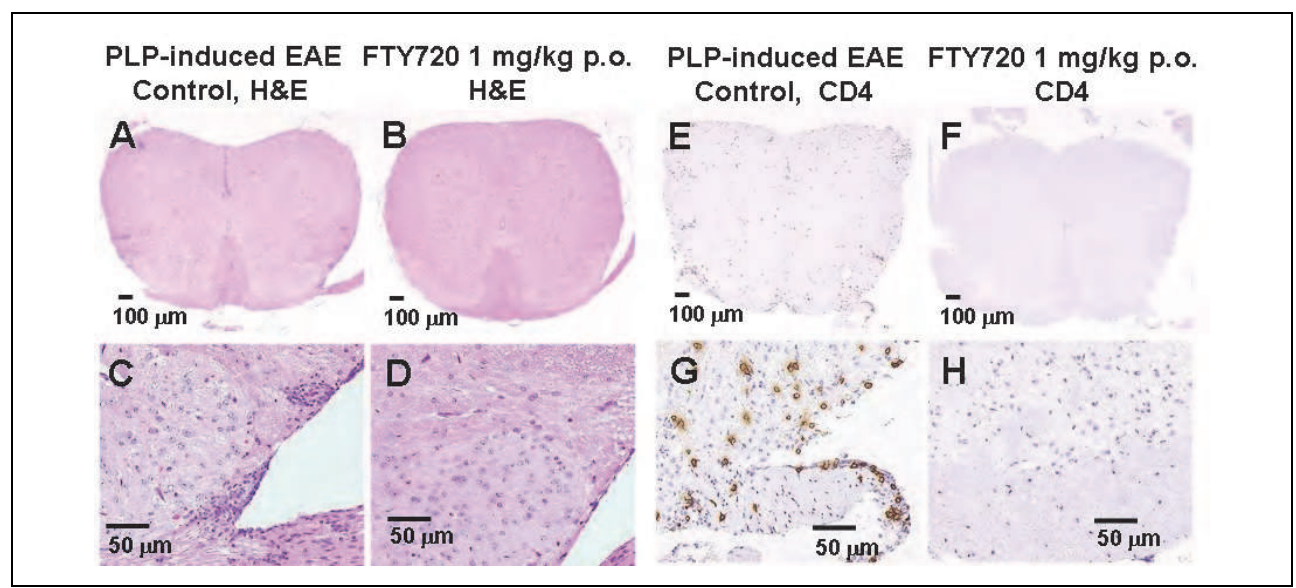

Fig. 6. Prophylactic administration of FTY720 decreased the infiltration of CD4+ ${ }^{+}$cells into the spinal cord of EAE mice induced by $\mathrm{PLP}_{139-151}$ immunization. SJL/J mice were immunized with PLP $139-151$ and administered FTY720 at $1 \mathrm{mg} / \mathrm{kg}$ p.o. prophylactically. On day 17 after immunization, the spinal cords of EAE-developed mice were obtained, and haematoxylin and eosin (H\&E) and immunohistochemical staining with anti mouse CD4 monoclonal antibody $(\mathrm{mAb})$ were performed.

\subsection{Therapeutic effects of FTY720 on PLP-induced EAE in SJL/J mice}

To evaluate the therapeutic effect of FTY720 on PLP $139-151$-induced, relapsing EAE in SJL/J mice, EAE-developed mice were pooled, divided into 4 groups consisting of six mice, and administration of FY720 was started 17 days after immunization (Kataoka et al., 2005). EAEassociated clinical signs had decreased rapidly by day 21, and thereafter, relapse of EAE occurred in the vehicle-treated control group (Fig. 7A). By contrast, the relapse of EAE was markedly inhibited and no EAE-associated clinical signs were observed from day 32 to 59 in groups given FTY720 at 0.3 and $1 \mathrm{mg} / \mathrm{kg}$ therapeutically, indicating complete inhibition of EAE relapse. In the group given rm-IFN- $\beta$ at 10000 IU three times a week intraperitoneally, the EAE score was significantly lowered at day 24, and relapse was delayed; however rmIFN- $\beta$ failed to inhibit the relapse of EAE. In another experiment, it was confirmed that the magnitude of the therapeutic effect of FTY720 is almost equal to that of prednisolone (1 $\mathrm{mg} / \mathrm{kg}$ p.o.) (Fig. 7B). In the group given FTY720 at $1 \mathrm{mg} / \mathrm{kg}$ therapeutically, the area of demyelination and the infiltration of $\mathrm{CD}^{+}{ }^{+} \mathrm{T}$ cells into the spinal cord were decreased as compared with the vehicle-treated control group (Fig. 8). Similarly, the relapse of EAE was markedly inhibited in groups given FTY720-P at 0.1 and $1 \mathrm{mg} / \mathrm{kg}$ therapeutically (Kataoka et al., 2005). 


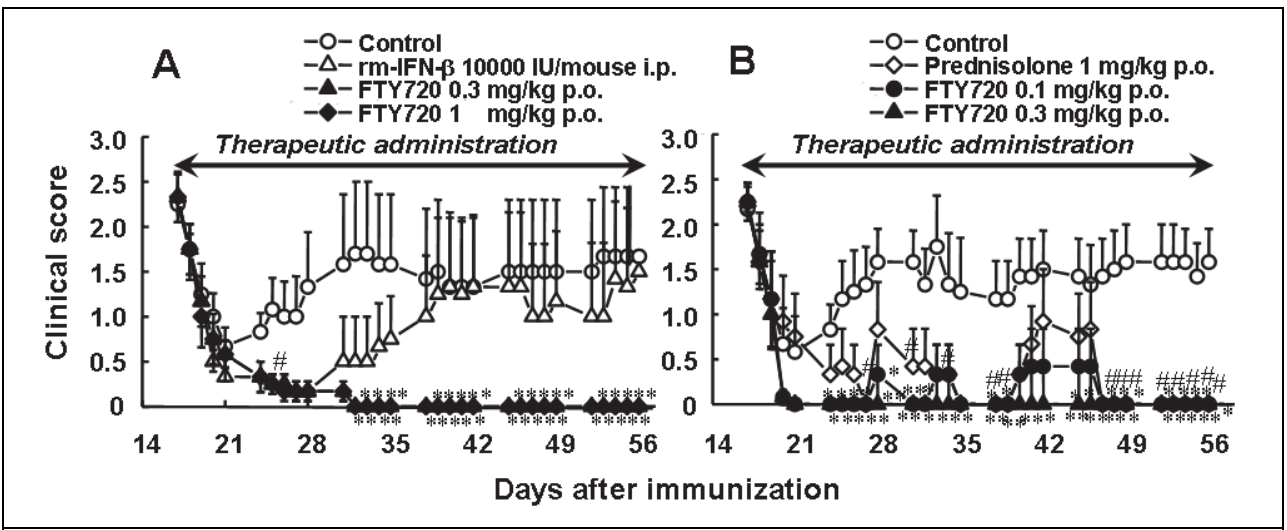

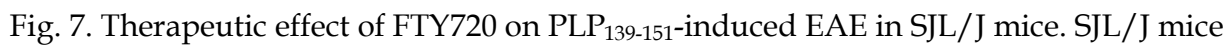
were immunized with PLP $_{139-151}(50 \mu \mathrm{g} /$ mouse) and Freund's complete adjuvant. EAEdeveloped mice were pooled, divided into 4 groups and administrations of FTY720 (daily), rm-IFN- $\beta$ (3 times a week), and prednisolone (daily) were started from day 17 . The results are expressed as the mean \pm S.E.M of 7 animals and statistical differences in clinical scores of FTY720 groups were calculated by Steel's test $\left({ }^{*}: \mathrm{p}<0.05,{ }^{* *}: \mathrm{p}<0.01\right)$, and those in rm-IFN- $\beta$ or prednisolone were done by Mann Whitney $U$ test $(\#: \mathrm{p}<0.05)$.

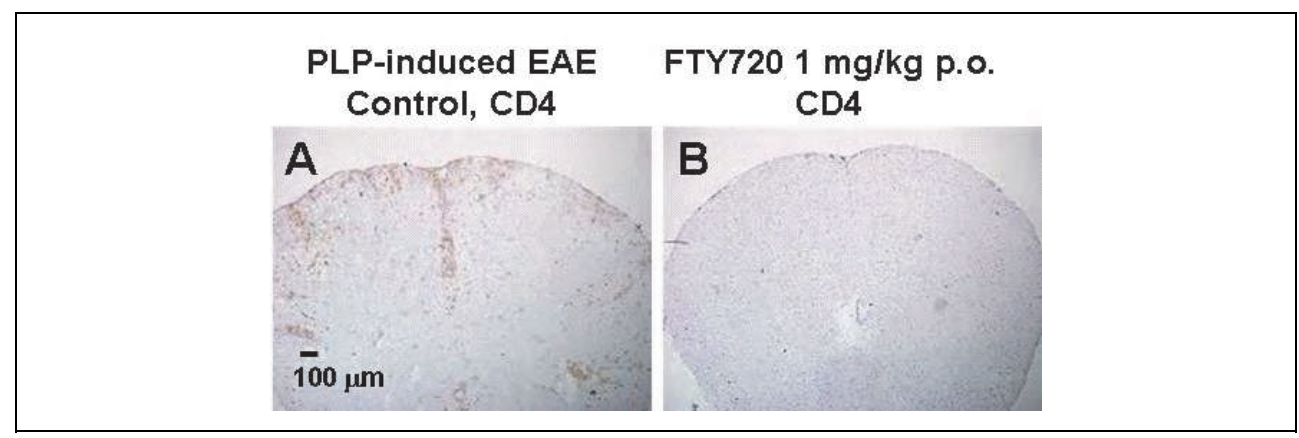

Fig. 8. Therapeutic administration of FTY720 decreased infiltration of CD4 ${ }^{+}$T cells into spinal cords of PLP $\mathrm{P}_{139-151-i n d u c e d}$ EAE mice. SJL/J mice were immunized with $\mathrm{PLP}_{139-151}$ and were administered FTY720 $(1 \mathrm{mg} / \mathrm{kg}$ p.o.) therapeutically from day 17 . The spinal cords of EAE-developed mice were obtained on day 28 , and were performed immunohistochemical staining with anti-mouse CD4 mAb.

\subsection{FTY720 shows a superior efficacy as compared with IFN- $\beta$ in the relapse of EAE induced by PLP in SJL/J mice}

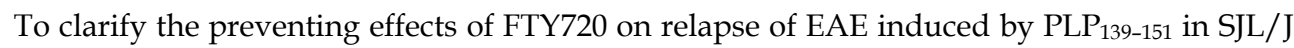
mice, EAE-developed mice were pooled on day 15 after immunization, divided into 5 groups, and administered vehicle or FTY720 (oral doses of $0.03,0.1,0.3$ and $1 \mathrm{mg} / \mathrm{kg}$ ) daily for 28 days (Fig. 9A) (Chiba et al., 2011). In vehicle-treated control group, the first phase of EAE was remitted with low EAE scores by day 8 after primary administration; however 
EAE symptoms were relapsed on day 10 to day 14 spontaneously, reached to maximal level on day 16, and maintained with high severity thereafter. The relapse of EAE was significantly inhibited in all of FTY720 groups and no clinical symptoms were observed in the groups given FTY720 at 0.3 and $1 \mathrm{mg} / \mathrm{kg}$ from day 12 to day 28 after primary administration. As shown in Fig. 11B, all 12 mice in the control group experienced the relapse of EAE from day 6 to day 16 after primary administration. FTY720 $(0.03$ to $1 \mathrm{mg} / \mathrm{kg})$ significantly prolonged the time to confirm the relapse of EAE and no relapse was seen in group given FTY720 at 0.3 and $1 \mathrm{mg} / \mathrm{kg}$, indicating an almost complete prevention for the relapse of EAE (Fig. 9B).

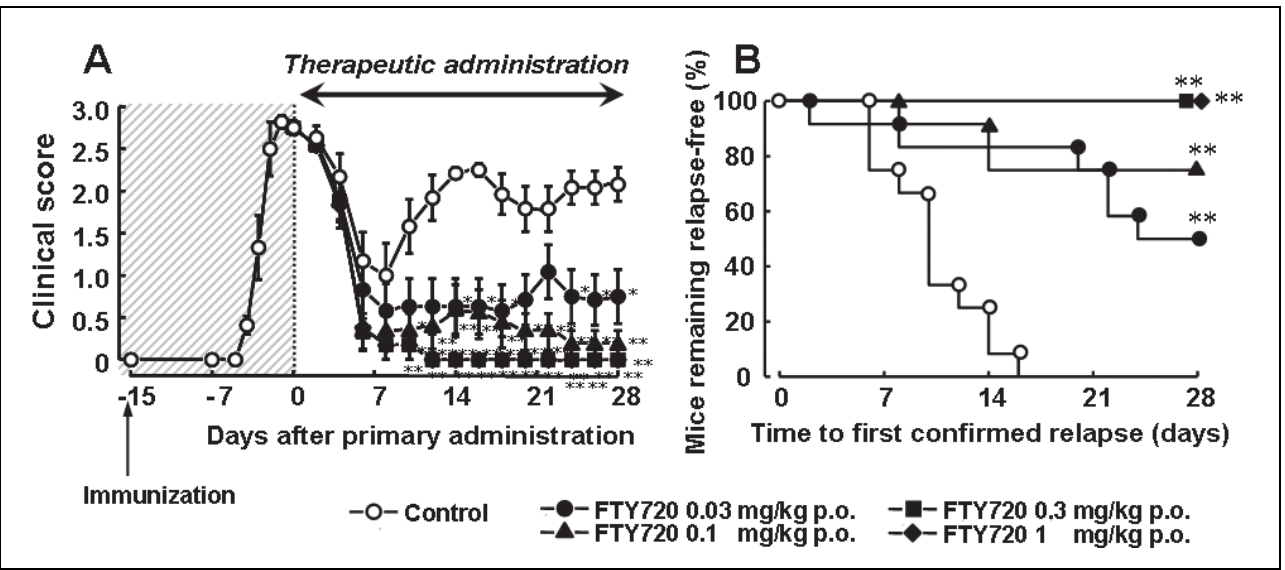

Fig. 9. Therapeutic effects of FTY720 on EAE induced by PLP ${ }_{139-151}$ in SJL/J mice. SJL/J mice were immunized with PLP $_{139-151}(50 \mu \mathrm{g} /$ mouse $)$ and Freund's complete adjuvant. EAEdeveloped mice were divided into 5 groups on day 15 day after immunization and administered vehicle or FTY720 orally every day for 28 days. (A) Clinical scores are expressed as the mean \pm S.E.M. of 12 mice. Statistical differences in EAE scores were calculated by Steel's test $\left({ }^{*}: \mathrm{p}<0.05,{ }^{* *}: \mathrm{p}<0.01\right.$ versus vehicle-treated control group). (B) Results are expressed as the proportion of mice remaining relapse-free in total 12 mice. Statistical differences were calculated by generalized Wilcoxon test adjusted by Holm's multiple comparison test $(* *: p<0.01$ versus vehicle-treated control group).

Next, we directly compared the therapeutic effects of FTY720 and rm-IFN- $\beta$ on relapsingremitting EAE induced by $\mathrm{PLP}_{139-151}$ in SJL/J mice. EAE-developed SJL/J mice were divided into 5 groups on day 15 after immunization and then administered vehicle, FTY720 (0.1 and $0.3 \mathrm{mg} / \mathrm{kg}$ p.o., daily), or rm-IFN- $\beta$ (3000 and $10000 \mathrm{IU} /$ mouse, subcutaneously every other day) for 28 days (Chiba et al. 2011). The relapse of EAE was markedly inhibited in groups given FTY720 at 0.1 and $0.3 \mathrm{mg} / \mathrm{kg}$ (Fig. 10A). The administration of rm-IFN- $\beta$ at low dose (3000 IU/mouse) resulted in only a slight but not significant inhibition on day 14 after primary administration. The high dose (10000 IU/mouse) of rm-IFN- $\beta$ showed a significant reduction of EAE scores, suggesting a delay of the relapse in early period of administration; however even high dose of rm-IFN- $\beta$ failed to prevent the relapse of EAE in latter period (Fig. 10B). 

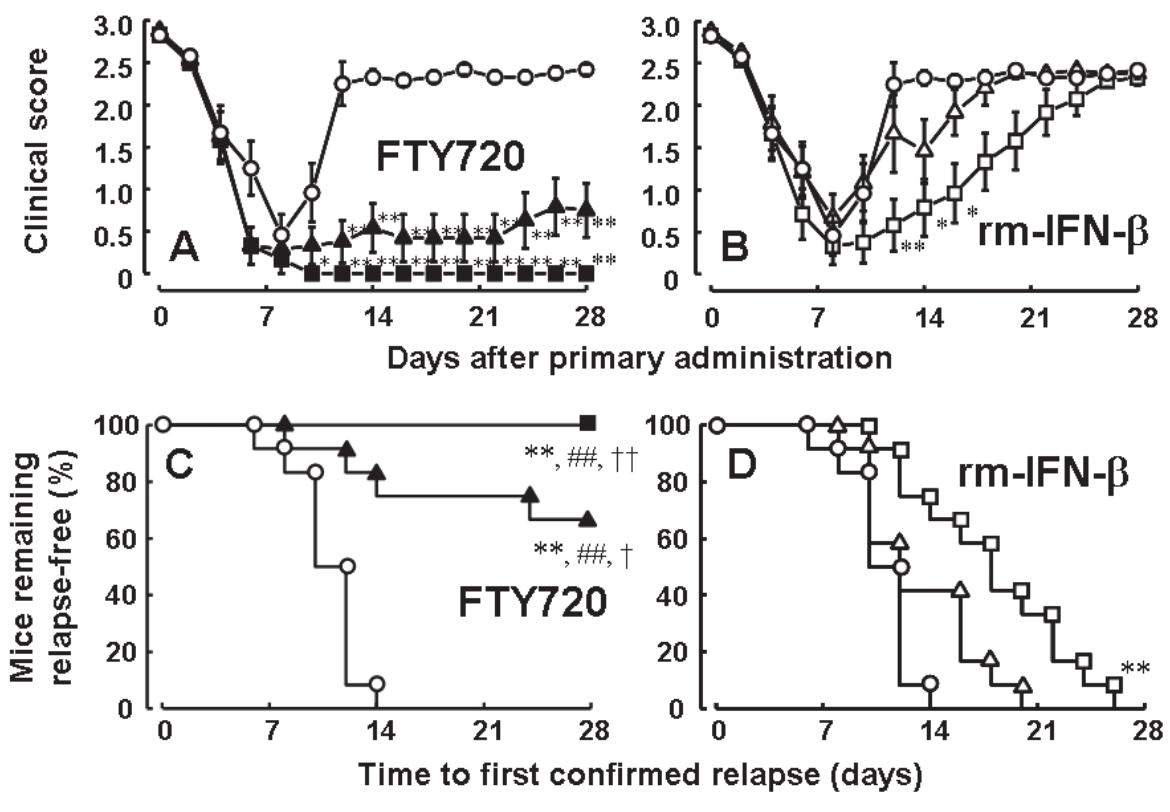

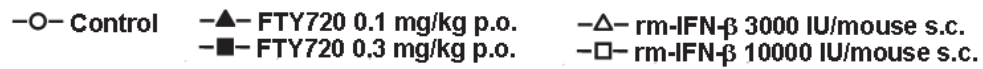

Fig. 10. Therapeutic effects of FTY720 and rm-IFN- $\beta$ on relapsing remitting EAE induced by $\mathrm{PLP}_{139-151}$ in SJL/J mice. EAE-developed mice were divided into 5 groups on day 15 after the immunization. Clinical scores are expressed as the mean \pm S.E.M. of 12 mice. (A) Statistical differences in clinical scores of EAE were calculated by Steel's test $\left({ }^{*}: p<0.05,{ }^{* *}: p<0.01\right.$ versus control). (B) Results are expressed as the proportion of mice remaining relapse-free in total 12 mice. Statistical differences were calculated by generalized Wilcoxon test adjusted by Holm's multiple comparison test $\left({ }^{* *}: \mathrm{p}<0.01\right.$ versus vehicle-treated control, \#\#: $\mathrm{p}<0.01$ versus rm-IFN- $\beta 3,000 \mathrm{IU} /$ mouse, $\uparrow: p<0.05, \uparrow \dagger: p<0.01$ versus rm-IFN- $\beta$ 10,000 IU/mouse).

All mice in the control group experienced the relapse of EAE from day 6 to day 14. FTY720 at 0.1 and $0.3 \mathrm{mg} / \mathrm{kg}$ significantly prolonged the time to first confirmed relapse and no relapse was seen in $0.3 \mathrm{mg} / \mathrm{kg}$ group (Fig 10C). In the high dose of rm-IFN- $\beta$ group, the relapse of EAE was significantly delayed; however all mice given rm-IFN- $\beta$ experienced the relapse of EAE (Fig. 10D). Furthermore, FTY720 significantly prolonged the time to first confirmed relapse as compared with rm-IFN- $\beta$, indicating that FTY720 shows a superior efficacy for preventing the relapse of EAE as compared with rm-IFN- $\beta$.

\subsection{FTY720 reduces infiltration of Th17 cells and Th1 cells into the spinal cords of PLP-induced EAE in SJL/J mice}

To elucidate the effects of FTY720 on demyelination and infiltration of CD4 ${ }^{+} \mathrm{T}$ cells into the CNS in EAE induced by PLP $_{139-151}$, the spinal cords were obtained from EAE mice given FTY720 or vehicle on day 28 after immunization. 


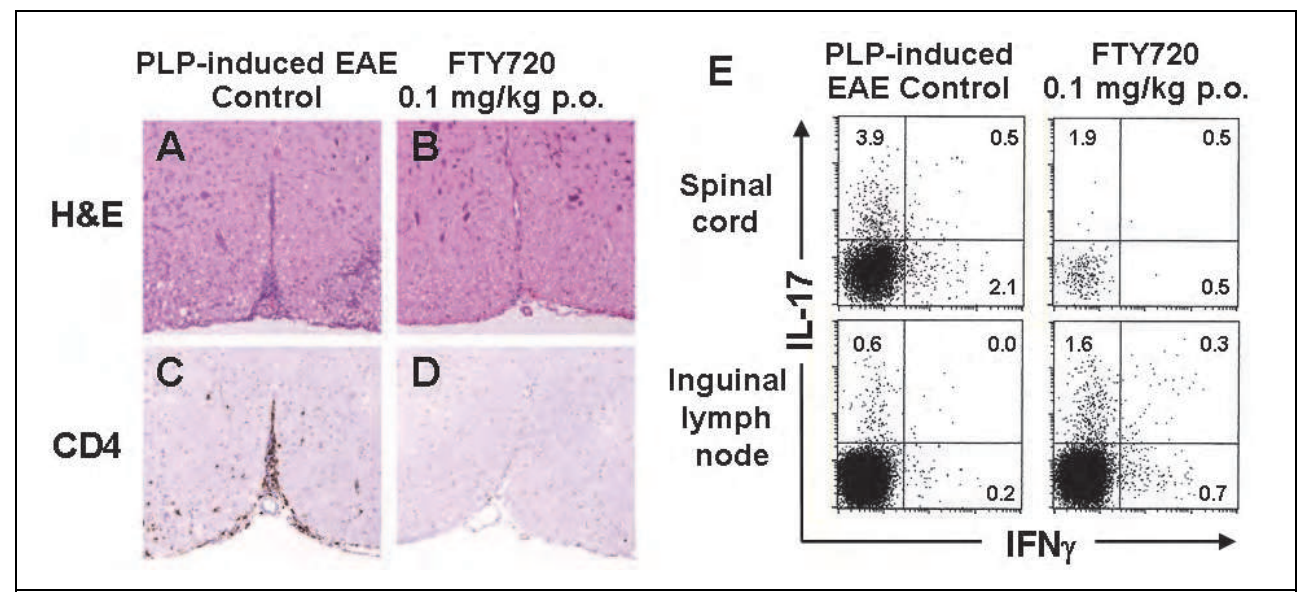

Fig. 11. Effects of FTY720 on the frequency of PLP-specific Th1 and Th17 cells in the spinal cords and inguinal lymph nodes in EAE mice immunized with $\mathrm{PLP}_{139-151}$. SJL/J mice were immunized with PLP ${ }_{139-151}(50 \mu \mathrm{g} /$ mouse) and Freund's complete adjuvant. EAE-developed mice were administered FTY720 at an oral dose of $0.1 \mathrm{mg} / \mathrm{kg}$ therapeutically for 28 days. On the next day of the final administration, the spinal cords were obtained and were stained with H\&E (A) control, (B) FTY720 $0.1 \mathrm{mg} / \mathrm{kg}$. Immunohistochemical staining of the spinal cords was performed by using anti-mouse CD4 mAb: (C) control, (D) FTY720 $0.1 \mathrm{mg} / \mathrm{kg}$. On the same day, lymphocytes were prepared from the spinal cords or inguinal lymph nodes of EAE mice and were cultured for $72 \mathrm{~h}$ in the presence of $\mathrm{PLP}_{139-151}(50 \mu \mathrm{g} / \mathrm{ml})$. After the culture, intracellular cytokine staining was performed by using anti-mouse CD4, anti-mouse IL-17, and anti-mouse IFN-ץ mAbs (E).

Demyelination and infiltration of inflammatory cells including lymphocytes were observed in the spinal cord of EAE mice in vehicle-treated control group (Fig. 11A). Therapeutic oral administration of FTY720 at $0.1 \mathrm{mg} / \mathrm{kg}$ resulted in a marked reduction of demyelination and infiltration of inflammatory cells in the spinal cord of EAE mice (Fig. 11B). By immunohistochemical staining using anti-mouse $\mathrm{CD} 4 \mathrm{mAb}$, it was revealed that $\mathrm{CD} 4^{+} \mathrm{T}$ cells were infiltrated into the spinal cord, particularly the perivascular area and funiculus dorsalis in white matter under pia matter of EAE mice (Fig. 11C). Therapeutic administration of FTY720 at $0.1 \mathrm{mg} / \mathrm{kg}$ orally resulted in a marked reduction of infiltration of CD4+ $4^{+}$cells into the spinal cord (Fig. 11D).

To clarify the involvement of myelin antigen-specific Th17 and Th1 cells, lymphocytes were prepared from the spinal cord and inguinal lymph nodes of EAE mice induced by immunization of PLP $\mathrm{P}_{139-151}$ on day 28 after immunization (Chiba et al., 2011). The obtained lymphocytes were re-stimulated with $\mathrm{PLP}_{139-151}$ for $72 \mathrm{~h}$ in vitro. Then, the numbers of PLPspecific Th17 cells and Th1 cells were determined by intracellular cytokine staining using anti-mouse CD4, anti-IL-17, and anti-IFN-ץ mAbs. Fig. 11E shows a typical pattern of intracellular cytokine staining of CD4-gated Th17 cells and Th1 cells in the spinal cord and inguinal lymph nodes in EAE mice. Significant numbers of Th17 and Th1 cells were found in the spinal cord from EAE mice, indicating the infiltration of myelin PLP-specific 
Th17 and Th1 cells into the CNS of EAE mice. FTY720 $(0.1 \mathrm{mg} / \mathrm{kg})$ markedly reduced the infiltration of PLP-specific Th17 and Th1 cells into the spinal cord of EAE mice (Chiba et al., 2011). On the contrary, FTY720 increased the frequency of PLP-specific Th17 and Th1 cells in inguinal lymph nodes to approximately 3-fold, suggesting inhibition of egress of PLP-specific Th cells from draining lymph nodes. From these results, therapeutic effects of FTY720 on EAE are likely due to reduction of infiltration of myelin antigen-specific Th cells into the CNS.

\section{Effects of FTY720 on MOG-induced EAE in C57BL/6 mice}

\subsection{Prophylactic and therapeutic effects of FTY720 on MOG-induced EAE in C57BL/6 mice}

When C57BL/ 6 mice were immunized with MOG $_{35-55}$ in the presence of Freund's complete adjuvant, chronic progressing EAE was developed on day 11 and reached a maximal level on day 17 after the immunization. Prophylactic administration of FTY720 at an oral dose of $0.3 \mathrm{mg} / \mathrm{kg}$ resulted in a marked delay in the onset of EAE and a significant reduction of EAE symptoms during the administration period (Fig. 12A) (Seki et al, 2010).

To examine the therapeutic effects of FTY720 on EAE induced by immunization with MOG $_{35-55}$ in C57BL/ 6 mice, EAE-established mice were divided into 3 groups consisting of eleven mice 17 days after the immunization (Kataoka et al., 2005). When FTY720 (0.1 and 0.3 $\mathrm{mg} / \mathrm{kg}$ ) was administered therapeutically, the symptoms of EAE were significantly improved during the administration period (Fig. 12B).

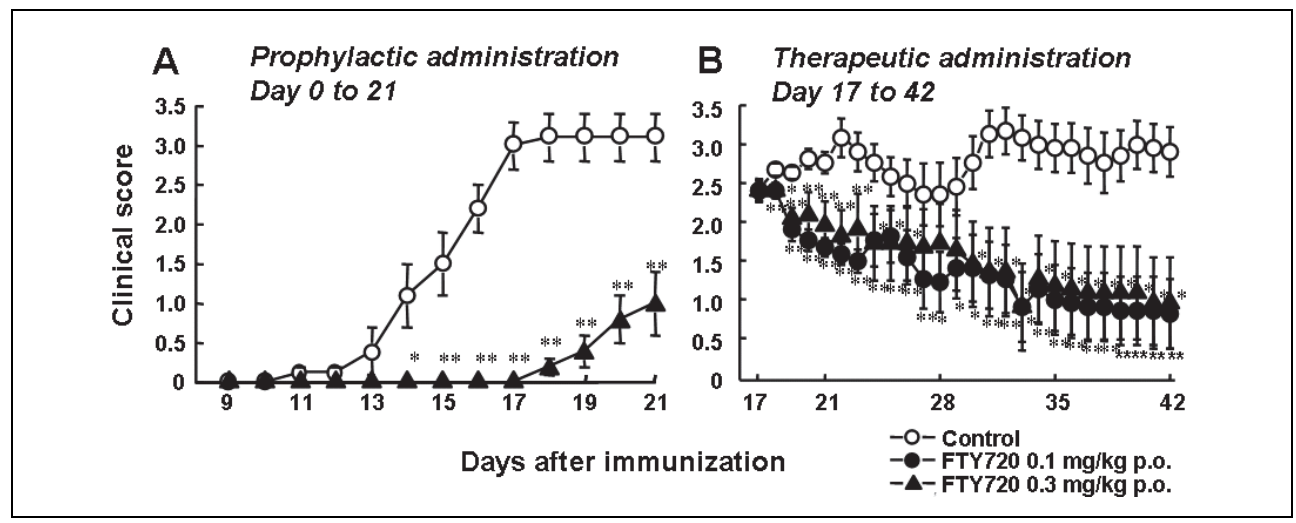

Fig. 12. Prophylactic and therapeutic effects of FTY720 on $\mathrm{MOG}_{35-55}$-induced EAE in C57BL/ 6 mice. C57BL/ 6 mice were immunized with MOG $_{35-55}(200 \mu \mathrm{g} / \mathrm{mouse})$ in the presence of Freund's complete adjuvant. (A) Prophylactic administration of FTY720 was stared on the day of the immunization for 21 days. (B) EAE-developed mice were pooled, divided into 3 groups and therapeutic administration of FTY720 was started from day 17 for 25 days. Clinical scores are expressed as the mean \pm S.E.M. of 10 to 11 mice. Statistical differences were calculated by Mann-Whitney $U$ test $(A)$ or Steel's test $(B){ }^{*}: p<0.05,{ }^{* *}$ : $\mathrm{p}<0.01)$. 
To compare the therapeutic effects of FTY720 and rm-IFN- $\beta$ on chronic EAE induced by $\mathrm{MOG}_{35-55}$ in C57BL/ 6 mice, EAE-developed mice were divided into 5 groups on day 15 after immunization with MOG $_{35-55}$, and administered vehicle or FTY720 (oral doses of 0.03, 0.1, 0.3 and $1 \mathrm{mg} / \mathrm{kg}$ ) daily for 28 days (Chiba et al., 2011). Therapeutic administration of FTY720 at 0.1 to $1 \mathrm{mg} / \mathrm{kg}$ significantly improved the EAE-associated symptoms during administration period (Fig. 13A). On the other hand, rm-IFN- $\beta$ (subcutaneous injection at $10,000 \mathrm{IU} /$ mouse every other day) showed no clear effect on chronic EAE induced by $\mathrm{MOG}_{35-55}$ (Fig. 13B).

\subsection{FTY720 reduces infiltration of Th17 and Th1 cells into the spinal cords of EAE mice induced by immunization with MOG}

Demyelination and infiltration of inflammatory cells including lymphocytes were observed in the spinal cord of EAE mice in vehicle-treated control group (Fig. 14A). Therapeutic oral administration of FTY720 at $0.3 \mathrm{mg} / \mathrm{kg}$ resulted in a marked reduction of demyelination and infiltration of inflammatory cells in the spinal cord of EAE mice (Fig. 14B). By immunohistochemical staining using anti-mouse $\mathrm{CD} 4 \mathrm{mAb}$, it was revealed that $\mathrm{CD} 4^{+} \mathrm{T}$ cells were infiltrated into the spinal cord of EAE mice (Fig. 14C). Therapeutic administration of FTY720 at $0.1 \mathrm{mg} / \mathrm{kg}$ orally resulted in a marked reduction of infiltration of CD4+ $\mathrm{T}$ cells into the spinal cord (Fig. 14D).

To examine the influence of FTY720 on infiltration of Th17 and Th1 cells into the CNS in MOG $35-55$-induced EAE in C57BL/6 mice, the spinal cords were obtained from EAE mice

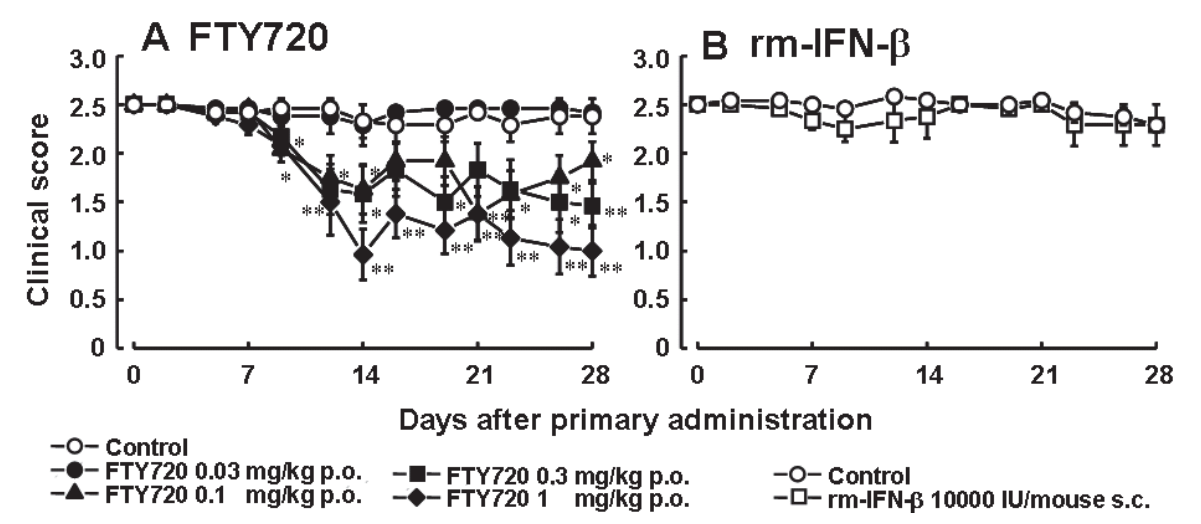

Fig. 13. Therapeutic effects of FTY720 and rm-IFN- $\beta$ on chronic EAE induced by MOG $35-55$ in C57BL/ 6 mice. C57BL/ 6 mice were immunized with MOG $_{35-55}(200 \mu \mathrm{g} / \mathrm{mouse})$ and EAEdeveloped mice were divided into 5 groups on day 14 after immunization. (A) FTY720 was administered orally every day for 28 days. (B) rm-IFN- $\beta$ was administered subcutaneously every other day for 28 days. Clinical scores are expressed as the mean \pm S.E.M. of 12 mice. Statistical differences in EAE scores were calculated by Steel's test $\left({ }^{*}: \mathrm{p}<0.05,{ }^{* *}: \mathrm{p}<0.01\right.$ versus control group). There was no significant difference between control group and rmIFN- $\beta$-treated group by Wilcoxon test. 
given FTY720 or vehicle for 16 days. Th17 and Th1 cells infiltrated into the spinal cords were determined by intracellular cytokine staining with mAbs against IL-17 and IFN- $\gamma$. Fig. 14E shows a typical pattern of intracellular cytokine staining of CD4-gated IL-17-expressing Th17 cells and IFN-ү-expressing Th1 cells in the lymphocytes infiltrated into the spinal cords in EAE mice (Seki et al., 2010). The number of CD4+ $\mathrm{T}$ cells infiltrated into the spinal cords was markedly decreased to less than $10 \%$ of control EAE mice by prophylactic administration of FTY720 at $0.3 \mathrm{mg} / \mathrm{kg}$ for 16 days. Moreover, the frequency of Th17 and Th1 cells in the spinal cords of EAE mice given FTY720 was also markedly decreased compared with control (Fig. 14E). On the contrary, the frequency of Th17 and Th1 cells in draining inguinal lymph nodes was increased to approximately 2 -fold by the administration of FTY720, suggesting that myelin antigen-specific Th cells can not exit from draining lymph nodes into periphery by treatment with FTY720.

FTY720-P, an active metabolite of FTY720, is known to show an agonistic activity on S1P receptors; however it acts as a functional antagonist of S1P1, because it strongly internalizes S1P1 receptor and reduces S1P responsiveness of lymphocytes (Brinkmann et al 2002, 2004; Chiba, 2005; Cyster, 2005; Maeda et al., 2007, Matloubian et al., 2004; Pham et al., 2008). As reported previously, mouse $\mathrm{CD} 4^{+} \mathrm{T}$ cells shows a migratory respond to a physiological concentration $(10 \mathrm{nM})$ of $\mathrm{S} 1 \mathrm{P}$ and the S1P responsiveness of $\mathrm{CD}^{+}{ }^{+} \mathrm{T}$ cells is almost completely inhibited by pretreatment with 0.3 to $3 \mathrm{nM}$ FTY720-P. To know whether myelin antigen-specific Th17 and Th1 cells generated in draining lymph nodes can respond a

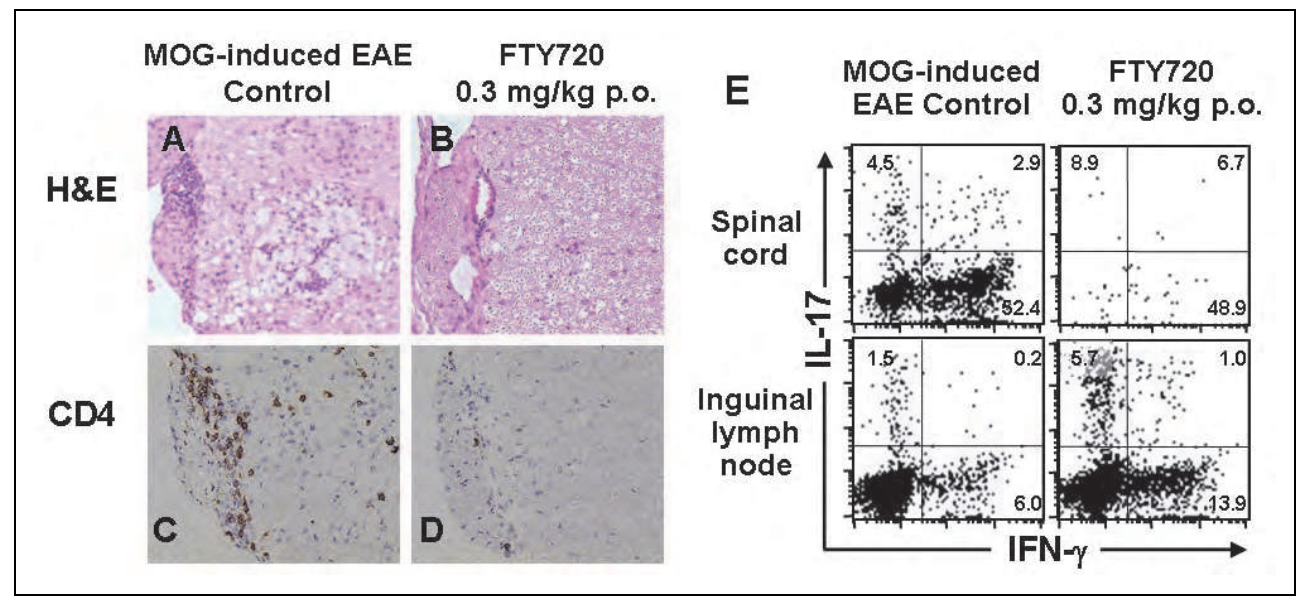

Fig. 14. Effects of FTY720 on the frequency of Th1 and Th17 cells in the spinal cords and inguinal lymph nodes in EAE mice immunized with $\mathrm{MOG}_{35-55}$. C57BL/ 6 mice were immunized with P MOG $35-55$ (200 $\mu \mathrm{g} /$ mouse) and EAE-developed mice were administered FTY720 at an oral dose of $0.1 \mathrm{mg} / \mathrm{kg}$ therapeutically for 28 days. On the next day of the final administration, the spinal cords were obtained and were stained with $\mathrm{H} \& \mathrm{E}(\mathrm{A})$ control, (B) FTY720 $0.3 \mathrm{mg} / \mathrm{kg}$. Immunohistochemical staining of the spinal cords was performed by using anti-mouse CD4 mAb: (C) control, (D) FTY720 $0.3 \mathrm{mg} / \mathrm{kg}$. On the same day, lymphocytes were prepared from the spinal cords or inguinal lymph nodes of EAE mice and intracellular cytokine staining was performed by using anti-mouse CD4, anti-mouse IL-17, and anti-mouse IFN- $\gamma$ mAbs (E). 
physiological concentration of S1P, we performed migration assays toward S1P using lymphocytes from draining inguinal lymph nodes of EAE-established mice. Both Th17 and Th1 cells prepared from the draining lymph nodes of EAE mice could migrate toward $10 \mathrm{nM}$ S1P and the migratory response of these Th cells toward S1P was almost completely inhibited by pretreatment with $1 \mathrm{nM}$ of FTY720-P (Seki et al., 2010). On the other hand, FTY720-P up to $100 \mathrm{nM}$ showed no clear effect on the generation of either Th17 or Th1 cells from naïve CD4 ${ }^{+} \mathrm{T}$ cells in vitro (Seki et al., 2010). Moreover FTY720-P did not affect IL-17 production from Th17 cells or IFN- $\gamma$ production from Th1 cells in vitro (Seki et al., 2010). From these results, it is suggested that FTY720-P converted from FTY720 inhibits egress of myelin antigen-specific Th17 and Th1 cells from draining lymph nodes, reduces infiltration of these Th cells into the CNS, and shows ameliorating effects on EAE in mice.

\section{Therapeutic effects of FTY720 in relapsing remitting MS}

The first clinical evidence that FTY720 has the therapeutic benefits in MS was provided in a 6-month, placebo-controlled Phase II trial involving 281 patients with relapsing remitting MS (RRMS) (Kappos et al., 2006). Patients receiving FTY720 at an oral dose of $1.25 \mathrm{mg}$ or 5.0 mg daily had a significant lower median total number of gadolinium-enhancing lesions (the primary end point) on magnetic resonance imaging (MRI) than those receiving placebo. The annualized relapse rates in groups given $1.25 \mathrm{mg}$ and $5.0 \mathrm{mg}$ of FTY720 were 0.35 and 0.36, respectively and were significantly lower than that in the placebo group (0.77). By extension study for additional 6 months, the number of gadolinium-enhanced lesions and relapse rates remained low in groups given FTY720 and both measures decreased in patients who switched from placebo to FTY720.

In FTY720-treated MS patients, the number of IL-17-expressing CD4 ${ }^{+} \mathrm{T}$ cells were reduced by $>95 \%$ in the peripheral blood suggesting that FTY720 inhibits egress of Th17 cells from the SLO and reduces the infiltration of Th17 cells into the CNS (Brinkman, 2009; Mehling et al., 2010). In addition, FTY720 primarily reduced the numbers of CCR7 ${ }^{+} \mathrm{CD}_{4}$ RA ${ }^{+}$naïve $\mathrm{T}$ cells and CCR7 ${ }^{+}$CD45RA- central memory T cells in the blood in MS patients, because these $\mathrm{T}$ cells express the homing receptor CCR7, recirculate through the lymph nodes, and can be sequestered into the lymph nodes by FTY720. In contrast, CCR7- CD45RA- and CCR7CD45RA+ effector memory $\mathrm{T}$ cell subsets are not sequestered into the SLO and are remained in the blood when FTY720 is administered. These results suggest that FTY720 effectively inhibits infiltration of pathogenic $\mathrm{CD}^{+} \mathrm{T}$ cells including Th 17 cells into the CNS in MS patients whereas FTY720 does not affect the function of effector memory T cells that play an important role in the prevention of infection.

FTY720 was evaluated in a 24-month, double blind Phase III study (FREEDOMS study), involving 1272 patients RRMS (Kappos et al., 2010). The patients were randomized to receive a daily oral dose of FTY720 at $0.5 \mathrm{mg}$ or $1.25 \mathrm{mg}$, or placebo. The annualized relapse rates in groups given $0.5 \mathrm{mg}$ and $1.25 \mathrm{mg}$ of FTY720 were 0.18 and 0.16 , respectively and were significantly lower than that in the placebo group (0.40). FTY720 at $0.5 \mathrm{mg}$ and $1.25 \mathrm{mg}$ significantly reduced the risk of disability progression over 24-month period. The cumulative probability of disability progression confirmed after 3 months was $17.7 \%$ with $0.5 \mathrm{mg}$ FTY720, 16.6\% with $1.25 \mathrm{mg}$ FTY720, and 24.1\% with placebo. FTY720 at $0.5 \mathrm{mg}$ and $1.25 \mathrm{mg}$ showed improved effects compared with placebo with regard to the MRI-related 
measures (number of new or enlarged lesions on T2-weightend images, gadoliniumenhanced lesions, and brain-volume loss).

FTY720 was also evaluated in a 12-month, double blind, double dummy Phase III study (TRANSFORMS study) involving 1292 patients with relapsing remitting MS, comparing FTY720 with IFN- $\beta$-1a (AVONEX ${ }^{\circledR}$ ), an established therapy for MS (Cohen et al., 2010). Patients were randomized to receive a daily dose of $0.5 \mathrm{mg}$ or $1.25 \mathrm{mg}$ FTY720 orally, or a weekly intramuscular injection of IFN- $\beta-1$ a. The annualized relapse rates in groups given FTY720 $0.5 \mathrm{mg}$ and $1.25 \mathrm{mg}$ were 0.16 and 0.20 respectively, and were significantly lower than that in the group receiving IFN- $\beta-1 \mathrm{a}(0.33)$. FTY720 at $0.5 \mathrm{mg}$ and $1.25 \mathrm{mg}$ showed improved effects compared with IFN- $\beta-1 \mathrm{a}$ with regard to MRI-related measures. These Phase III studies demonstrated that oral FTY720 had superior efficacy compared with intramuscular IFN- $\beta-1 \mathrm{a}$ and placebo with regard to reducing the rate of relapse and MRIrelated measures of inflammatory lesion activity. Based on these results from clinical trials, FTY720 was approved by the United States Food and Drug Administration in September 2010 as a first-line treatment for RRMS. As FTY720 has been approved more than 40 countries including EU at this time, it is presumed that oral FTY720 provides a new therapeutic approach for RRMS.

\section{Conclusion}

FTY720, a S1P receptor modulator, acts as a functional antagonist at S1P1 and is highly effective in EAE in rats and mice. We directly compared the therapeutic effects of FTY720 and rm-IFN- $\beta$ on relapse and progression of EAE in mice. When FTY720 at oral doses of 0.03 to $1 \mathrm{mg} / \mathrm{kg}$ was administered daily after establishment of EAE induced by myelin PLP in $\mathrm{SJL} / \mathrm{J}$ mice, relapse of EAE was significantly inhibited during administration period. Subcutaneous injection of rm-IFN- $\beta$ (10,000 IU/mouse) also inhibited the relapse of EAE at early period; however EAE was relapsed in all the mice within administration period. Therapeutic administration of FTY720 (0.03 to $1 \mathrm{mg} / \mathrm{kg})$ significantly improved the symptoms of chronic EAE induced by myelin oligodendrocyte glycoprotein in C57BL/6 mice whereas rm-IFN- $\beta$ (10,000 IU/mouse) showed no clear effect. These results indicate that FTY720 is more efficacious in mouse EAE as compared with rm-IFN- $\beta$. FTY720 markedly reduced the frequency of myelin antigen-specific Th17 and Th1 cells in the spinal cord of EAE mice, suggesting that the ameliorating effects of FTY720 on EAE are likely due to reduction of infiltration of myelin antigen-specific Th17 and Th1 cells into the CNS. Recently, it has been strongly suggested that FTY720-P directly acts as a functional antagonist at S1P1 on not only lymphocytes but also neural cells, particularly astrocytes because the therapeutic effects of FTY720 on EAE was lost in CNS mutants lacking S1P1 on astrocytes but not neuron. Since FTY720 possesses a completely new mechanism of action and shows superior efficacy compared with intramuscular IFN- $\beta-1 \mathrm{a}$ (AVONEX ${ }^{\circledR}$ ) in relapsing remitting MS patients, FTY720 should be a useful therapeutic approach for MS.

\section{Acknowledgment}

The authors thank Mamoru Koyama, Kyoko Shimano, Mikako Murase, Sachiko Mochiduki, Dr. Yasuhiro Maeda, Dr. Atsushi Fukunari, and Dr. Kunitomo Adachi, Mitsubish Tanabe Pharma Corporation, for their fruitful collaborations. 


\section{References}

Adachi, K.; Kohara, T.; Nakao, N.; Arita, M.; Chiba, K.; Mishina, T.; Sasaki, S. \& Fujita, T. (1995). Design, synthesis and structure-activity relationships of 2-substituted-2amino-1,3-propanediols: discovery of a novel immunosuppressant, FTY720. BioMed. Chem. Lett., Vol. 5, pp. 853-856

Anderson, S. A.; Shukaliak-Quandt, J.; Jordan, E. K. et al. (2004). Magnetic resonance imaging of labeled T-cells in a mouse model of multiple sclerosis. Ann. Neurol., Vol. 55, pp. 654-659

Balatoni, B.; Storch, MK.; Swoboda, E. M.; Schonborn, V.; Koziel, A.; Lambrou, G. N. et al. (2007). FTY720 sustains and restores neuronal function in the DA rat model of MOG-induced experimental autoimmune encephalomyelitis. Brain Res. Bull., Vol. 74, pp. 307-316

Bettelli, E.; Carrier, Y.; Gao, W.; Korn, T.; Strom, T. B.; Oukka, M. et al. (2006). Reciprocal developmental pathways for the generation of pathogenic effector TH17 and regulatory T cells. Nature, Vol. 441, pp. 235-238.

Billich, A.; Bornancin, F.; Devay, P.; Mechtcheriakova, D.; Urtz, N. \& Baumruker, T. (2003). Phosphorylation of the immunomodulatory drug FTY720 by sphingosine kinases. J. Biol. Chem. Vol. 278, pp. 47408-47415

Bright, J. J.; Du, C.; Coon, M.; Sriram, S. \& Klaus, S. J. (1998). Prevention of experimental allergic encephalomyelitis via inhibition of IL-12 sgnaling and IL-12-mediated Th1 differentiation: an effect of the novel anti-inflammatory drug lisofylline. $J$. Immunol., Vol. 161, pp. 7015-7022.

Brinkmann, V.; Pinschewer, D.; Chiba, K. \& Feng, L. (2000). FTY720: a novel transplantation drug that modulates lymphocyte traffic rather than activation. Trends in Pharmacological Sciences, Vol. 21, pp. 49-52

Brinkmann, V.; Davis, M. D.; Heise, C. E.; Albert, R.; Cottens, S.; Hof, R.; Bruns, C.; Prieschl, E.; Baumruker, T.; Hiestand, P.; Foster, C. A.; Zollinger, M. \& Lynch, K. R. (2002a). The immune modulator FTY720 targets sphingosine 1-phosphate receptors. J. Biol. Chem., Vol. 277, pp. 21453-21457

Brinkmann, V. \& Lynch, K. R. (2002b). FTY720: target G-protein-coupled receptors for sphingosine 1-phosphate in transplantation and autoimmunity. Curr. Opin. Immunol., Vol. 14, pp. 569-575

Brinkmann, V.; Cyster, J. G. \& Hla, T. (2004). FTY720: sphingosine 1-phosphate receptor-1 in the control of lymphocyte egress and endothelial barrier function. Am. J. Transplant. Vol. 4, pp. 1019-1025

Brinkmann, V. (2009). FTY720 (fingolimod) in Multiple Sclerosis: therapeutic effects in the immune and the central nervous system. Br. J. Pharmacol., Vol. 158, pp 1173-1182

Chiba, K.; Hoshino, Y.; Suzuki, C.; Masubuchi, Y.; Yanagawa, Y.; Ohtsuki, M.; Sasaki, S. \& Fujita, T. (1996). FTY720, a novel immunosuppressant possessing unique mechanisms I. Prolongation of skin allograft survival and synergistic effect in combination with cyclosporin A in rats. Transplant. Proc., Vol. 28, pp. 1056-1059

Chiba, K. \& Adachi, K. (1997). FTY720, immunosuppressant. Drugs of the Future, Vol. 22, pp. $18-22$

Chiba, K.; Yanagawa, Y.; Masubuchi, Y.; Kataoka, H.; Kawaguchi, T.; Ohtsuki, M. \& Hoshino, Y. (1998). FTY720, a novel immunosuppressant, induces sequestration of circulating mature-lymphocytes by acceleration of lymphocyte homing in rats. I. 
FTY720 selectively decreases the number of circulating mature lymphocytes by acceleration of lymphocyte homing. J. Immunol., Vol. 160, pp. 5037-5044

Chiba, K.; Yanagawa, Y.; Kataoka, H.; Kawaguchi, T.; Ohtsuki, M. \& Hoshino, Y. (1999). FTY720, a novel immunosuppressant, induces sequestration of circulating lymphocytes by acceleration of lymphocyte homing. Transplant. Proc., Vol. 31, pp. 1230-1233

Chiba, K.; Hoshino, Y.; Ohtsuki, M.; Kataoka, H.; Maeda, Y.; Matsuyuki, K.; Sugahara, K.; Kiuchi, M.; Hirose, R. \& Adachi, K. (2005). Imunosuppressive activity of FTY720, sphingosine 1-phosphate receptor agonist: I. Prevention of allograft rejection in rats and dogs by FTY720 and FTY720-phosphate. Transplant. Proc., Vol. 37, pp. 102-106

Chiba, K. (2005). FTY720, a new class of immunomodulator, inhibits lymphocyte egress from secondary lymphoid tissues and thymus by agonistic activity at sphingosine 1-phosphate receptors. Pharmacol. Ther., Vol. 108, pp. 308-319

Chiba, K.; Matsuyuki, H.; Maeda, Y. \& Sugahara, K. (2006). Role of sphingosine 1-phosphate receptor type 1 in lymphocyte egress from secondary lymphoid tissues and thymus. Cell. Mol. Immunol., Vol. 3, pp. 11-19

Chiba, K. (2010). Sphingosine 1-phosphate receptor type 1 as a novel target for the therapy of autoimmune diseases. Inflamm. Regen. Vol. 30, pp. 160-168

Chiba, K.; Kataoka, H.; Seki, N.; Shimano, K.; Koyama, M.; Fukunari, A.; Sugahara, K. \& Sugita T. (2011). Fingolimod (FTY720), sphingosine 1-phosphate receptor modulator, shows superior efficacy as compared with interferon- $\beta$ in mouse experimental autoimmune encephalomyelitis. Int. Immunopharmacol., Vol. 11, pp. 366-372

Choi, J. W.; Gardell, S. E.; Herr, D. R.; Rivera, R.; Lee, C.-W.; Noguchi, K. et al. (2011). FTY720 (fingolimod) efficacy in an animal model of multiple sclerosis requires astrocyte sphingosine 1-phosphate receptor 1 (S1P1) modulation. Proc. Natl. Acad. Sci. USA., Vol. 108, pp. 751-756

Cohen, J. A.; Barkhof, F.; Comi, G.; Hartung, H. P.; Khatri, B. O.; Montalban, X. et al. (2010). Oral fingolimod or intramuscular interferon for relapsing multiple sclerosis. $N$. Engl. J. Med., Vol. 362, pp. 402-415

Cyster, J. G. (2005). Chemokines, sphingosine-1-phosphate, and cell migration in secondary lymphoid organs. Annu. Rev. Immunol. Vol. 23, pp. 127-159.

Foster, C. A.; Howard, L. M.; Schweitzer, A.; Persohn, E. Hiestand, P. C.; Balatoni, B. et al. (2007). Brain penetration of the oral immunomodulatory drug FTY720 and its phosphorylation in the central nervous system during experimental autoimmune encephalomyelitis: consequences for mode of action in multiple sclerosis. $J$. Pharmacol. Exp. Ther. Vol. 323, pp. 469-475

Fujino, M.; Funeshima, N.; Kitazawa, Y.; Kimura, H.; Amemiya, H.; Suzuki, S. \& Li, X. K. (2003). Amelioration of experimental autoimmune encephalomyelitis in Lewis rats by FTY720 treatment. J. Pharmacol. Exp. Ther., Vol. 305, pp. 70-77

Fujita, T.; Inoue, K.; Yamamoto. S.; Ikumoto, T.; Sasaki, S.; Toyama, R.; Chiba, K.; Hoshino. Y. \& Okumoto, T. (1994a). Fungal metabolites. Part 11. A potent immunosuppressive activity found in Isaria sinclairii metabolite. J. Antibiotics, Vol. 47, pp. 208-215

Fujita, T.; Inoue, K., Yamamoto, S.; Ikumoto, T.; Sasaki, S.; Toyama, R.; Chiba, K.; Hoshino, Y. \& Okumoto, T. (1994b). Fungal metabolites. Part 12. Potent immunosuppressant, 
14-deoxomyruiocin, $(2 S, 3 R, 4 R)$-(E)-2-amino-3,4-dihydroxy-2-hydroxymethyleicos6-enoic acid and structure-activity relationships of myriocin derivatives. $J$. Antibiotics, Vol. 47, pp. 216-224

Fujita, T.; Yoneta, M.; Hirose, R.; Sasaki, S.; Inoue, K.; Kiuchi, M.; Hirase, S.; Adachi, K.; Arita, M. \& Chiba, K. (1995). Simple compounds, 2-alkyl-2-amino-1,3-propane-diols have potent immunosuppressive activity. BioMed. Chem. Lett., Vol. 5, pp. 847-852

Fujita, T.; Hirose, R.; Yoneta, M.; Sasaki, S.; Inoue, K.; Kiuchi, M.; Hirase, S.; Chiba, K.; Sakamoto, H. \& Arita, M. (1996). Potent immunosuppressants, 2-alkyl-2aminopropane-1,3-diols. J. Med. Chem., Vol. 39, pp. 4451-4459

Goodkin, D. E.; Reingold, S.; Sibley, W. et al. (1999). Guide lines for clinical trials for new therapeutic agents in multiple sclerosis: reporting extended results from phase III clinical trials-National Multiple Sclerosis Society Advisory Committee on Clinical Trials of New Agents in Multiple sclerosis. Ann. Neurol., Vol. 46, pp. 132-134

Graler, M. H. \& Goetzl, E. J. (2004). The immunosuppressant FTY720 down-regulates sphingosine 1-phosphate G-protein-coupled receptors. FASEB J. Vol. 18, pp. 551553.

Hla, T.; Lee, M. J.; Ancellin, N.; Paik, J. H. \& Kluk, M. J. (2001). Lysophospholipids - receptor revelations. Science, Vol. 294, pp. 1875-1878

Hoshino, Y.; Suzuki, C.; Ohtsuki, M.; Masubuchi, Y.; Amano, Y. \& Chiba, K. (1996). FTY720, a novel immunosuppressant possessing unique mechanisms II. Long-term graft survival induction in rat hetrotopic cardiac allograft and synergistic effect in combination with cyclosporin A. Transplant. Proc., Vol. 28, pp. 1060-1061

Kataoka, H.; Sugahara, K.; Shimano, K,; Teshima, K.; Koyama, M.; Fukunari, A. \& Chiba, K. (2005). FTY720, sphingosine 1-phosphate receptor modulator, ameliorates experimental autoimmune encephalomyelitis by inhibition of $\mathrm{T}$ cell infiltration. Cell. Mol. Immunol. Vol. 2, pp. 439-448

Kappos, L.; Antel, J.; Comi, G.; Montalban, X.; O'Connor, P.; Polman, C. H. et al. (2006). Oral fingolimod (FTY720) for relapsing multiple sclerosis. N. Engl. J. Med., Vol. 355, pp. 1124-1140

Kappos, L.; Radue, E. W.; O'Connor, P.; Polman, C.; Hohlfeld, R.; Calabresi, P. et al. (2010). A placebo-controlled trial of oral fingolimod in relapsing multiple sclerosis. $N$. Engl. J. Med., Vol. 362, pp. 387-401

Kawaguchi, T.; Hoshino, Y.; Rahman, F.; Amano, Y.; Higashi, H.; Kataoka, H.; Ohtsuki, M.; Teshima, K.; Chiba. K.; Kakefuda, T. \& Suzuki, S. (1996). FTY720, a novel immunosuppressant possessing unique mechanisms III. Synergistic prolongation of canine renal allograft survival in combination with cyclosporin A. Transplant. Proc., Vol. 28, pp. 1062-1063

Kimura, Y.; Sato, K.; Kuwabara, A.; Tomura, H.; Ishikawa, M.; Kobayashi, I.; Ui, M. \& Okajima, F. (2001). Sphingosine 1-phosphate may be a major component of plasma lipoproteins responsible for the cytoprotective actions in human umbilical vein endothelial cells. J. Biol. Chem. Vol. 276, pp. 31780-31785

Kiuchi, M.; Adachi, K.; Kohara, T.; Minoguchi, M.; Hanano, T.; Aoki, Y.; Mishina, T.; Arita, M.; Nakao, N.; Ohtsuki, M.; Hoshino, Y.; Teshima, K.; Chiba, K.; Sasaki, S. \& Fujita, T. (2000). Synthesis and immunosuppressive activity of 2-substituted 2aminopropane-1,3-diols and 2-aminoethanols. J. Med. Chem., Vol. 43, pp. 2946-2961 
Kiuchi, M.; Adachi, K.; Tomatsu, A.; Chino, M.; Takeda, S.; Tanaka, Y.; Maeda, Y.; Sato, N.; Mitsutomi, N.; Sugahara, K. \& Chiba, K. (2005). Asymmetric synthesis and biological evaluation of the enantiomeric isomer of immunosuppressive FTY720phosphate. Bioorg. Med. Chem., Vol. 13, pp 425-432

Komiyama, Y.; Nakae, S.; Matsuki, T.; Nambu, A.; Ishigame, H.; Kakuta, S. et al. (2006). IL17 plays an important role in the development of experimental autoimmune encephalomyelitis. J. Immunol., Vol. 177, pp. 566-573

Kroenke, M. A.; Carlson, T. J.; Andjelkovic, A. V. \& Segal, B. M. (2008). IL-12- and IL-23modulated T cells induce distinct types of EAE based on histology, CNS chemokine profile, and response to cytokine inhibition. J. Exp. Med., Vol. 205, pp. 1535-1541

Kuchroo, V. K.; Martin, C. A.; Greer, J. M.; Ju, S. T.; Sobel, R. A. \& Dorf, M. E. (1993). Cytokines and adhesion molecules contribute to the ability of myelin proteolipid protein-specific T cell clones to mediate experimental allergic encephalomyelitis. J. Immunol., Vol. 151, pp. 4371-4382

Langrish, C. L.; Chen, Y.; Blumenschein, W. M.; Mattson, J.; Basham, B.; Sedgwick, J. D. et al. (2005). IL-23 drives a pathogenic $T$ cell population that induces autoimmune inflammation. J. Exp. Med., Vol. 201, pp. 233-240

Li, H.; Meno-Tetang, G. L.; Chiba, K.; Arima, N.; Heinig, P. \& Jusko, W. L. (2002). Pharmacokinetics and cell trafficking dynamics of 2-amino-2-[2-(4-octylphenyl) ethyl]propane-1,3-diol hydrochloride (FTY720) in cynomolgus monkeys after single oral and intravenous doses. J. Pharmacol. Exp. Ther., Vol. 301, pp. 519-526

Lo, C. G.; Xu, Y.; Proia, R. \& Cyster, J. G. (2005). Cyclical modulation of sphingosine-1phosphate receptor 1 surface expression during lymphocyte recirculation and relationship to lymphoid organ transit. J. Exp. Med., Vol. 201, pp. 291-301

Lublin, F. D. \& Reingold, S. C. (1996). Defining the clinical course of multiple sclerosis: results of an international survey. National Multiple Sclerosis Society (USA) Advisory Committee on Clinical Trials of New Agents in Multiple Sclerosis. Neurology, Vol. 46, pp. 907-911.

Maeda, Y.; Matsuyuki, H.; Shimano, K.; Kataoka, H.; Sugahara, K. \& Chiba, K. (2007). Migration of CD4 T cells and dendritic cells toward sphingosine 1-phosphate (S1P) is mediated by different receptor subtypes: S1P regulates the functions of murine mature dendritic cells via S1P receptor type 3. J. Immunol., Vol. 178, pp. 3437-3446

Mandala, S.; Hajdu, R.; Bergstrom, J.; Quackenbush, E.; Xie, J.; Milligan, J.; Thornton, R.; Shei, G.-J.; Card, D.; Keohane, C.; Rosenbach, M.; Hale, J.; Lynch, C. L.; Rupprecht, K.; Parsons, W. \& Rosen, H. (2002). Alteration of lymphocyte trafficking by sphingosine-1-phosphate receptor agonists. Science, Vol. 296, pp. 346-349

Martin, R.; McFarland, H. F. \& McFarlin, D. E. (1992). Immunological aspects of demyelinating diseases. Annu. Rev. Immunol., Vol. 10, pp. 153-187

Martin, R. \& McFarland, H. F. (1995). Immunological aspects of experimental allergic encephalomyelitis and multiple sclerosis. Crit. Rev. Clin. Lab. Sci., Vol. 32, pp. 121182

Masubuchi, Y.; Kawaguchi, T.; Ohtsuki, M.; Suzuki, C.; Amano, Y.; Hoshino, Y. \& Chiba, K. (1996). FTY720, a novel immunosuppressant possessing unique mechanisms IV. Prevention of graft versus host reactions in rats. Transplant. Proc., Vol. 28, pp. 10641065 
Matloubian, M.; Lo, C. G.; Cinamon, G.; Lesneski, M. J.; Xu, Y.; Brinkmann, V.; Allende, M.; Proia, R. \& Cyster, J. G. (2004). Lymphocyte egress from thymus and peripheral lymphoid organs is dependent on S1P receptor 1. Nature, Vol. 427, pp. 355-360

Mehling, M.; Lindberg, R.; Raulf, F.; Kuhle, J.; Hess, C., Kappos, L. \& Brinkmann, V. (2010) Th17 central memory T cells are reduced by FTY720 in patients with multiple sclerosis. Neurology, Vol. 75, pp. 403-410.

Merrill, J. E., Kono, D. H.; Clayton, J.; Ando, D. G.; Hinton, D. R. \& Hofman, F. M. (1992). Inflammatory leukocytes and cytokines in peptide-induced disease of experimental allergic encephalomyelitis in SJL and B10.PL mice. Proc. Natl. Acad. Sci. USA., Vol. 89 , pp. 574-578

Owens, T. \& Sriram, S. (1995). The immunology of multiple sclerosis and its animal model, experimental allergic encephalomyelitis. Neurol. Clin., Vol. 13, pp 51-73

Paugh, S. W.; Payne, S. G.; Barbour, S. E.; Milstien, S. \& Spiegel, S. (2003). The immunosuppressant FTY720 is phosphorylated by sphingosine kinase type 2. FEBS Lett., Vol. 554, pp. 189-193

Pham, T. H.; Okada, T.; Matloubian, M.; Lo, C. G. \& Cyster, J. G. (2008). S1P1 receptor signalling overrides retention mediated by $\mathrm{G}$ alpha i-coupled receptors to promote T cell egress. Immunity, Vol. 28, pp. 122-133

Pyne, S. \& Pyne, N. (2000). Sphingosine 1 phosphate signalling via the endothelial differentiation gene family of G-protein-coupled receptors. Pharmacol. Ther. Vol. 88, pp. 115-131

Rammohan, K. W. (2003). Axonal injury in multiple sclerosis. Curr. Neurol. Neurosci. Rep., Vol. 3, pp. 231-237.

Sasaki, S.; Hashimoto, R.; Kiuchi, M.; Inoue, K.; Ikumoto, T.; Hirose, R.; Chiba, K.; Hoshino, Y. \& Okumoto, T. (1994). Fungal metabolites. Part 14. Novel potent immunosuppressants, Mycestericins, produced by Mycelia sterilia. J. Antibiotics, Vol. 47, pp. 420-433

Seamons, A.; Perchellet, A. \& Goverman, J. (2003). Immune tolerance to myelin proteins. Immunol. Rev., Vol. 28, pp. 201-221

Seki, N.; Maeda, Y.; Kataoka, H.; Sugahara, K.; Sugita, T. \& Chiba, K. (2010). Fingolimod (FTY720) ameliorates experimental autoimmune encephalomyelitis (EAE): II. FTY720 decreases infiltration of Th17 and Th1 cells into the central nervous system in EAE. Inflamm. Regen. Vol. 30, pp. 545-551

Steinman, L. (2010). Mixed results with modulation of TH-17 cells in human autoimmune diseases. Nat. Immunol., Vol. 11, pp. 41-44

Stromnes, I. M.; Cerretti, L. M.; Liggitt, D.; Harris, R. A. \& Goverman, J. M. (2008). Differential regulation of central nervous system autoimmunity by $\mathrm{T}_{\mathrm{H}} 1$ and $\mathrm{T}_{\mathrm{H}} 17$ cells. Nat. Med., Vol. 14, pp. 337-342

Suzuki, S.; Enosawa, S.; Kakefuda, T.; Shinomiya, T.; Amari, M.; Naoe, S.; Hoshino, Y. \& Chiba, K. (1996) A novel immunosuppressant, FTY720, having an unique mechanism of action induces long-term graft acceptance in rat and dog allotransplantation. Transplantation, Vol. 61, pp. 200-205

Suzuki, S.; Kakefuda, T.; Amemiya, H.; Chiba, K.; Hoshino, Y.; Kawaguchi, T.; Kataoka, H. \& Rahman, F. (1998). An immunosuppressive regime using FTY720 combined with cyclosporin in canine kidney transplantation. Transpl. Int., Vol. 11, pp. 95-101 
Webb, M.; Tham, C. S.; Lin, F. F.; Lariosa-Willingham, K.; Yu, N.; Hale, J. et al. (2004). Sphingosine 1-phosphate receptor agonists attenuate relapsing-remitting experimental autoimmune encephalitis in SJL mice. J. Neuroimmunol., Vol. 153, pp. 108-121

Windhagen, A.; Newcombe, J.; Dangond, F. et al. (1995). Expression of costimulatory molecules B7-1 (CD80), B7-2 (CD86), and interleukin 12 cytokines in multiple sclerosis lesions. J. Exp. Med., Vol. 182, pp. 1985-1996

Yagi, H.; Kamba, R.; Chiba, K.; Soga, H.; Yaguchi, K.; Nakamura, M. \& Itoh, T. (2000). Immunosuppressant FTY720 inhibits thymocyte emigration. Eur. J. Immunol., Vol. 30, pp. 1435-1444

Yanagawa, Y.; Sugahara, K.; Kataoka, H.; Kawaguchi, T.; Masubuchi, Y. \& Chiba K. (1998a). FTY720, a novel immunosuppressant, induces sequestration of circulating mature lymphocytes by acceleration of lymphocyte homing in rats. II. FTY720 prolongs skin allograft survival by preventing infiltration of $\mathrm{T}$ cells into the grafts, but not production of cytokines in vivo. J. Immunol., Vol. 160, pp. 5493-5499.

Yanagawa, Y.; Masubuchi, Y. \& Chiba K. (1998b). FTY720, a novel immunosuppressant, induces sequestration of circulating mature lymphocytes by acceleration of lymphocyte homing in rats. III. Increase in frequency of CD62L-positive T cells in Peyer's patches by FTY720-induced lymphocyte homing. Immunology, Vol. 95, pp. 591-594

Yanagawa, Y.; Hoshino, Y.; Kataoka, H.; Kawaguchi, T.; Ohtsuki, M.; Sugahara, K. \& Chiba, K. (1999). FTY720, a novel immunosuppressant, prolongs rat skin allograft survival by decreasing T cell infiltration into grafts. Transplant. Proc., Vol. 31, pp. 1227-1229

Yanagawa, Y.; Hoshino, Y. \& Chiba, K. (2000). The significance of timing of FTY720 administration on the immunosuppressive effect to prolong rat skin allograft survival. Int. J. Immunopharmacol., Vol. 22, pp. 597-602

Zamvil, S. S. \& Steinman, L. (2003). Diverse targets for intervention during inflammatory and neurodegenerative phases of multiple sclerosis. Neuron, Vol. 38, pp. 685-688 


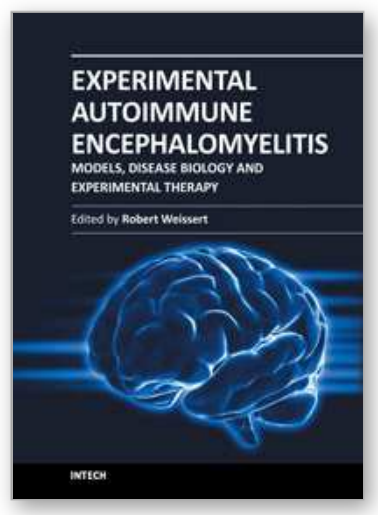

\author{
Experimental Autoimmune Encephalomyelitis - Models, Disease \\ Biology and Experimental Therapy \\ Edited by Prof. Robert Weissert
}

ISBN 978-953-51-0038-6

Hard cover, 162 pages

Publisher InTech

Published online 03, February, 2012

Published in print edition February, 2012

Experimental Autoimmune Encephalomyelitis - Models, Disease Biology and Experimental Therapy is totally focused on the model of multiple sclerosis, experimental autoimmune encephalomyelitis (EAE). The book chapters give a very good and in depth overview about the currently existing and most used EAE models. In addition, chapters dealing with novel experimental therapeutic approaches demonstrate the usefulness of the EAE model for MS research. With an international perspective, this book features contributions from authors throughout the world, Australia, Germany, Japan, Spain, Taiwan, and USA. There is an impressive international Faculty that provides insight into current research themes. This further demonstrates the importance of EAE in research all over the world. The book will provide established researchers and students with novel insights and guidance for their research and will help to push the field forward.

\title{
How to reference
}

In order to correctly reference this scholarly work, feel free to copy and paste the following:

Kenji Chiba, Hirotoshi Kataoka, Noriyasu Seki and Kunio Sugahara (2012). Therapeutic Effects of the Sphingosine 1-Phosphate Receptor Modulator, Fingolimod (FTY720), on Experimental Autoimmune Encephalomyelitis, Experimental Autoimmune Encephalomyelitis - Models, Disease Biology and Experimental Therapy, Prof. Robert Weissert (Ed.), ISBN: 978-953-51-0038-6, InTech, Available from:

http://www.intechopen.com/books/experimental-autoimmune-encephalomyelitis-models-disease-biology-andexperimental-therapy/therapeutic-effect-of-the-sphingosine-1-phosphate-receptor-modulator-fingolimodfty720-on-experiment

\section{INTECH}

open science | open minds

\section{InTech Europe}

University Campus STeP Ri

Slavka Krautzeka 83/A

51000 Rijeka, Croatia

Phone: +385 (51) 770447

Fax: +385 (51) 686166

www.intechopen.com

\section{InTech China}

Unit 405, Office Block, Hotel Equatorial Shanghai

No.65, Yan An Road (West), Shanghai, 200040, China 中国上海市延安西路65号上海国际贵都大饭店办公楼405单元

Phone: +86-21-62489820

Fax: +86-21-62489821 
(C) 2012 The Author(s). Licensee IntechOpen. This is an open access article distributed under the terms of the Creative Commons Attribution 3.0 License, which permits unrestricted use, distribution, and reproduction in any medium, provided the original work is properly cited. 